\title{
Chitinase 3-like 1 secreted from cancer-associated fibroblasts promotes tumor angiogenesis via interleukin-8 secretion in colorectal cancer
}

\author{
KAORI WATANABE, KAZUYOSHI SHIGA, ANRI MAEDA, SHINNOSUKE HARATA, \\ TAKESHI YANAGITA, TAKUYA SUZUKI, HAJIME USHIGOME, YUZO MAEDA, \\ TAKAHISA HIROKAWA, RYO OGAWA, MASAYASU HARA, HIROKI TAKAHASHI, \\ YOICHI MATSUO, AKIRA MITSUI, MASAHIRO KIMURA and SHUJI TAKIGUCHI \\ Department of Gastroenterological Surgery, Nagoya City University Graduate School of \\ Medical Sciences, Nagoya, Aichi 467-8601, Japan
}

Received September 2, 2021; Accepted November 19, 2021

DOI: $10.3892 /$ ijo.2021.5293

\begin{abstract}
The cancer-stromal interaction has been demonstrated to promote tumor progression, and cancer-associated fibroblasts (CAFs), which are the main components of stromal cells, have attracted attention as novel treatment targets. Chitinase 3-like 1 (CHI3L1) is a chitinase-like protein, which affects cell proliferation and angiogenesis. However, the mechanisms through which cells secrete CHI3L1 and through which CHI3L1 mediates tumor progression in the cancer microenvironment are still unclear. Accordingly, the present study assessed the secretion of CHI3L1 in the microenvironment of colorectal cancer and evaluated how CHI3L1 affects tumor angiogenesis. CAFs and normal fibroblasts (NFs) established from colorectal cancer tissue, and human colon cancer cell lines were evaluated using immunostaining, cytokine antibody array, RNA interference, reverse transcriptionquantitative PCR (RT-qPCR), ELISA, western blotting and angiogenesis assays. The expression and secretion of CHI3L1 in CAFs were stronger than those in NFs and colorectal cancer cell lines. In addition, interleukin-13 receptor $\alpha 2$ (IL-13R $\alpha 2$ ), a receptor for $\mathrm{CHI} 3 \mathrm{~L} 1$, was not expressed in colorectal cancer
\end{abstract}

Correspondence to: Dr Kazuyoshi Shiga, Department of Gastroenterological Surgery, Nagoya City University Graduate School of Medical Sciences, 1 Kawasumi, Mizuho-cho, Mizuho-ku, Nagoya, Aichi 467-8601, Japan

E-mail: kz-0926@med.nagoya-cu.ac.jp

Abbreviations: $\alpha$-SMA, $\alpha$-smooth muscle actin; bFGF, basic fibroblast growth factor; CAFs, cancer-associated fibroblasts; CHI3L1, chitinase 3-like 1; IL-13R $\alpha 2$, interleukin-13 receptor $\alpha 2$; mAY, human CHI3L1 neutralizing antibody; MCP-1, monocyte chemoattractant protein-1; NFs, normal fibroblasts; RT-qPCR, reverse transcription-quantitative PCR; si/siRNA, small interfering RNA; VEGF, vascular endothelial growth factor

Key words: CAF, CHI3L1, IL-8, colorectal cancer, angiogenesis cell lines, but was expressed in fibroblasts, particularly CAFs. Furthermore, the expression and secretion of IL- 8 in CAFs was stronger than that in NFs and cancer cell lines, and recombinant CHI3L1 addition increased IL-8 expression in CAFs, whereas knockdown of CHI3L1 suppressed IL-8 expression. Furthermore, IL-13R $\alpha 2$ knockdown suppressed the enhancement of IL-8 expression induced by CHI3L1 treatment in CAFs. For vascular endothelial growth factor-A (VEGFA), similar results to IL-8 were observed in an ELISA for comparison of secretion between CAFs and NFs and for changes in secretion after CHI3L1 treatment in CAFs; however, no significant differences were observed for changes in expression after CHI3L1 treatment or IL-13R $\alpha 2$ knockdown in CAFs assessed using RT-qPCR assays. Angiogenesis assays revealed that tube formation in vascular endothelial cells was suppressed by conditioned medium from CAFs with the addition of human CHI3L1 neutralizing antibodies compared with control IgG, and also suppressed by conditioned medium from CAFs transfected with CHI3L1, IL-8 or VEGFA small interfering RNA compared with negative control small interfering RNA. Overall, the present findings indicated that CHI3L1 secreted from CAFs acted on CAFs to increase the secretion of IL-8, thereby affecting tumor angiogenesis in colorectal cancer.

\section{Introduction}

Cancer tissue develops through the proliferation, migration, invasion and angiogenesis of cancer cells $(1,2)$. However, the interactions between cancer cells and the surrounding stromal cells (cancer-stromal interaction) have also been demonstrated to promote the progression of cancer $(1,2)$. Furthermore, cancerassociated fibroblasts (CAFs), which are the main components of stromal cells, are attracting attention as novel targets for anticancer treatment (3-5). CAFs, which are different from normal fibroblasts (NFs), are activated fibroblasts observed in the cancer stroma and have the characteristics of myofibroblasts, including expression of $\alpha$-smooth muscle actin ( $\alpha$-SMA) (6). CAFs can be isolated from various types of cancer, such as colorectal cancer, gastric cancer, pancreatic cancer, prostate 
cancer, breast cancer and lung cancer (7-12). However, to the best of our knowledge, the mechanisms of CAF development have not been clarified, and several types of cells have been reported as the origin of CAFs (4). For example, conversion from NFs (13), cancer cells that have undergone the epithelialmesenchymal transition $(14,15)$, endothelial cells that have undergone the endothelial-mesenchymal transition (16), bone marrow-derived mesenchymal stem cells $(17,18)$ and adipose tissue-derived stem cells (19) are considered to be potential origins of CAFs. However, the specific origins of CAFs have not yet been clarified.

CAFs have been reported to affect tumor progression, including proliferation, migration, invasion and angiogenesis $(3,5,7,14,20,21)$. Some of them have been demonstrated to be mediated in part by the secretion of cell adhesion molecules, growth factors and cytokines, such as IL-6 and vascular endothelial growth factor-A (VEGFA) for angiogenesis (7), basic fibroblast growth factor (bFGF) for proliferation (12), and monocyte chemoattractant protein-1 (MCP-1) for migration (20). In addition, some reports have revealed that CAFs are involved in drug resistance acquisition and cancer apoptosis $(9,22-24)$. Therefore, although these reports $(3,5,7,9,14,20-24)$ suggested that CAFs are involved in tumor progression through multiple mechanisms, the details of these mechanisms have not yet been elucidated.

Chitinase 3-like 1 (CHI3L1), a 40 kDa secreted glycoprotein also known as YKL-40 $(25,26)$, was originally considered to be associated with inflammatory diseases, such as asthma, liver fibrosis and arthritis (27-29). A number of reports have described the involvement of CHI3L1 in cancer (11,30-35). For example, serum CHI3L1 levels are associated with prognosis in patients with colorectal cancer (30), and upregulation of CHI3L1 expression in tumors promotes tumor angiogenesis, proliferation, migration, invasion and radiation resistance (31-33). Furthermore, CHI3L1 has been reported to be associated with tumor-associated macrophages $(11,33,34)$. However, the mechanisms of CHI3L1 production and the mechanisms through which CHI3L1 induces tumor progression have not been clarified. Although two reports have described the association of CHI3L1 and CAFs, the mechanisms were found to involve immune cells or exosomes rather than cytokine secretion $(11,35)$.

Therefore, the present study evaluated the interactions between CAFs and colorectal cancer cells mediated by CHI3L1 and cytokine secretion. The present findings clarified that CHI3L1, which was mainly secreted from CAFs, acted on CAFs themselves to increase the secretion of IL-8, which may promote tumor angiogenesis in colorectal cancer. To the best of our knowledge, this is the first report of the roles of CAFs in angiogenesis promoted by $\mathrm{CHI} 3 \mathrm{~L} 1$ in the microenvironment of colorectal cancer.

\section{Materials and methods}

Cell lines. The HT-29, HCT116 and DLD-1 human colorectal cancer cell lines and the EA.hy926 human umbilical vein endothelial cell line were purchased from American Type Culture Collection. These cancer cell lines have been authenticated (no. KBN0811) using short tandem repeat DNA analysis by the Japanese Collection of Research Bioresources Cell Bank.
HT-29, HCT116 and EA.hy926 cells were cultured in DMEM (Sigma-Aldrich; Merck KGaA) supplemented with 10\% FBS (Gibco; Thermo Fisher Scientific, Inc.) and 1\% penicillinstreptomycin solution (Gibco; Thermo Fisher Scientific, Inc.). DLD-1 cells were cultured in RPMI-1640 medium (SigmaAldrich; Merck KGaA) supplemented with $10 \%$ FBS and 1\% penicillin-streptomycin solution. All cells were incubated at $37^{\circ} \mathrm{C}$ in an atmosphere containing $5 \% \mathrm{CO}_{2}$.

Isolation and culture of human colon fibroblasts. Human colon fibroblasts used in present study were established from a specimen resected from a 70-year-old Japanese man with advanced well-differentiated colon adenocarcinoma at the Department of Gastroenterological Surgery, Nagoya City University (Nagoya, Japan) in April 2020. In the selection of the case, adenocarcinoma (grade of differentiation not considered) was used as an inclusion criterion, and small tumor for which the stromal components around the cancer could not be sufficiently sampled and perforation from which cancer and stool contamination could be detected were used as exclusion criteria. The technical procedure was the same as that described in a previous report (7). After obtaining written informed consent, tissues were retrieved from two separate areas: Near-cancerous tissue and normal colon tissue (10 cm from the cancer tissue). To avoid cancer and stool contamination, the tissues were collected from the serosal side with care to not penetrate the mucosa and to not cut into the cancer tissue. The tissue was fragmented with scissors into cubes measuring $\sim 2 \mathrm{~mm}^{3}$ and then incubated at $37^{\circ} \mathrm{C}$ for $2 \mathrm{~h}$ in DMEM containing 1,000 PU/ml Dispase (Godo Shusei Co., Ltd.). The fragments were cultured in DMEM containing $5 \%$ FBS and $1 \%$ penicillin-streptomycin solution and incubated at $37^{\circ} \mathrm{C}$ in an atmosphere containing $5 \% \mathrm{CO}_{2}$. These fibroblasts were used at passages 4-7.

Agents. Recombinant human CHI3L1 (cat. no. 2599-CH), recombinant human IL-8 (cat. no. 208-IL) and recombinant human VEGFA (cat. no. 293-VE) were purchased from R\&D Systems, Inc., and reconstituted with PBS to a concentration of $100 \mu \mathrm{g} / \mathrm{ml}$ and stored at $-20^{\circ} \mathrm{C}$. In the experiments, the recombinant CHI3L1, IL-8 and VEGFA were diluted in DMEM or RPMI-1640 medium as appropriate for each cell line to a final concentration of 100,100 and $50 \mathrm{ng} / \mathrm{ml}$, respectively, according to previous reports (11,31-33,36-39). Human CHI3L1 neutralizing antibody (mAY; mouse monoclonal antibody; cat. no. MABC196) was purchased from Sigma-Aldrich; Merck $\mathrm{KGaA}$, and $\mathrm{IgG}$ control (cat. no. MAB002) was purchased from $R \& D$ Systems, Inc. Both were reconstituted with PBS to concentrations of 1 and $0.5 \mathrm{mg} / \mathrm{ml}$, respectively, and stored at $-20^{\circ} \mathrm{C}$. For experiments, $\mathrm{mAY}$ and $\mathrm{IgG}$ control were diluted in medium and used at a concentration of $10 \mu \mathrm{g} / \mathrm{ml}$. The duration of action of the assays was based on previous reports $(7,11)$.

Immunostaining and immunofluorescence staining. The primary antibodies against vimentin (V9; cat. no. ab8069; Abcam), cytokeratin (AE1/AE3; cat. no. ab27988; Abcam), CD90 (5E10; cat. no. 555593; BD Biosciences), $\alpha-S M A$ (1A4; cat. no. ab7817; Abcam) and CHI3L1 (cat. no. ab77528; Abcam) were used for immunostaining and immunofluorescence staining. 
Immunohistochemistry was performed as previously described (40). The resected specimen was fixed with $10 \%$ formalin for 2 days at room temperature. Formalin-fixed, paraffin-embedded and 4- $\mu \mathrm{m}$-thick sections were deparaffinized with xylene and hydrated with ethanol at $100 \%$ twice, 90,80 and $70 \%$ for 5 min each. After washing with running water, samples were soaked in $10 \mathrm{mM}$ citric acid buffer and boiled using a microwave for $10 \mathrm{~min}$ at $100^{\circ} \mathrm{C}$. Subsequently, the slides were soaked in $100 \%$ methanol and $0.3 \%$ hydrogen peroxide mixed solution for $30 \mathrm{~min}$ to block endogenous peroxidase activity, and blocked with $4 \%$ Block Ace Powder (cat. no. UKB80; DS Pharma Biomedical Co., Ltd.) for $10 \mathrm{~min}$ in a humidity box at room temperature. Afterwards, slides were stained with the primary antibodies [anti-vimentin (dilution, 1:1,000), anti-cytokeratin (dilution, 1:100), anti- $\alpha$-SMA (dilution, 1:500) and anti-CHI3L1 (dilution, 1:500)] overnight at $4^{\circ} \mathrm{C}$. Subsequently, the sections were incubated with undiluted anti-mouse/rabbit EnVision+/HRP-labeled polymer (cat. no. K4001/K4003; Dako; Agilent Technologies, Inc.), as the secondary antibody, for $45 \mathrm{~min}$ at room temperature. The tissues were stained with 3,3'-diaminobendizine substrate (cat. no. K3467; Dako; Agilent Technologies, Inc.) for $10 \mathrm{~min}$ at room temperature and counterstained with hematoxylin for $30 \mathrm{sec}$ at room temperature. The slides were observed and analyzed using the BZ-X710 fluorescence microscope and BZ-X Analyzer software version 1.4.0.1 (both from Keyence Corporation) at a magnification of $\times 200$.

Immunostaining and immunofluorescence staining of cultured cells were performed as previously described (7). For immunostaining, cells grown in chamber slides were fixed with $4 \%$ paraformaldehyde buffer for $20 \mathrm{~min}$ at room temperature, treated with $0.1 \%$ Triton $\mathrm{X}$ for 3 min and blocked with $3 \%$ BSA (FUJIFILM Wako Pure Chemical Corporation)/PBS for $1 \mathrm{~h}$ at room temperature. Then, the primary antibodies [anti-vimentin (dilution, 1:80), anti-cytokeratin (dilution, 1:80), anti-CD90 (dilution, 1:100)] were applied for $1 \mathrm{~h}$ at room temperature. Subsequently, anti-mouse EnVision+/HRP-labeled polymer was applied undiluted as the secondary antibody for $1 \mathrm{~h}$ at room temperature. The cells were stained with anti-mouse 3,3'-diaminobendizine substrate (Dako; Agilent Technologies, Inc.) for $15 \mathrm{~min}$ at room temperature and counterstained with hematoxylin for $30 \mathrm{sec}$ at room temperature. The slides were observed and analyzed using the BZ-X710 fluorescence microscope and BZ-X Analyzer software version 1.4.0.1 at a magnification of $\mathrm{x} 40$.

For immunofluorescence staining, cells grown in chamber slides were fixed with $4 \%$ paraformaldehyde buffer for $20 \mathrm{~min}$ at room temperature, treated with $0.1 \%$ TritonX for $3 \mathrm{~min}$ and blocked with $3 \% \mathrm{BSA} / \mathrm{PBS}$ for $1 \mathrm{~h}$ at room temperature. Then, anti- $\alpha$-SMA mouse monoclonal antibody (dilution, 1:150) was applied as the primary antibody for $2 \mathrm{~h}$ at room temperature. Subsequently, goat anti-mouse IgG H\&L (Alexa Fluor 488; dilution, 1:200; cat. no. ab150113; Abcam) was applied as the secondary antibody for $30 \mathrm{~min}$ at room temperature. After washing with PBS, samples were mounted with ProLong Gold Antifade Reagent with 4',6-diamidino-2-phenylindole (Invitrogen; Thermo Fisher Scientific, Inc.). The slides were observed and analyzed using the BZ-X710 fluorescence microscope and BZ-X Analyzer software version 1.4.0.1 at a magnification of $\mathrm{x} 200$.
Cytokine antibody array. Fibroblasts were seeded in 6-well plates with DMEM containing $2 \% \mathrm{FBS}\left(5 \times 10^{4}\right.$ cells/well). After overnight incubation, the medium was exchanged ( $3 \mathrm{ml} /$ well). After $24 \mathrm{~h}$, the culture supernatants were collected and centrifuged at $400 \mathrm{x} \mathrm{g}$ for $5 \mathrm{~min}$ at $4^{\circ} \mathrm{C}$ to remove particulates, and $500 \mu \mathrm{l}$ of the supernatant was used for each array. A Proteome Profiler Human XL Cytokine Array kit (cat. no. ARY022B; $\mathrm{R} \& \mathrm{D}$ Systems, Inc.) was used according to the manufacturer's protocol. Images were captured using an LAS-3000 instrument (FUJIFILM Corporation) with each signal normalized to the positive controls.

RNA interference. CHI3L1 small interfering RNA (siRNA) (s3000), interleukin-13 receptor $\alpha 2$ (IL-13R $\alpha 2$ ) siRNA (s7376), VEGFA siRNA (s462) and non-targeting negative control siRNA (Silencer Select Negative Control No. 1; cat. no. 4390843) were pre-designed siRNAs purchased from Invitrogen; Thermo Fisher Scientific, Inc. IL-8 siRNA (cat. no. sc-39631) was also pre-designed siRNA purchased from Santa Cruz Biotechnology, Inc. CAFs were seeded at $1 \times 10^{5}$ cells/well in 6 -well plates for RT-qPCR, $2.5 \times 10^{4}$ cells/well in 24-well plates for ELISA and the angiogenesis assay, and $\sim 80 \%$ confluent in $10-\mathrm{cm}$ dishes for western blotting the day before siRNA transfection. According to the manufacturer's instructions, siRNAs and Lipofectamine RNAiMAX (Invitrogen; Thermo Fisher Scientific, Inc.) were mixed with Opti-MEM (Invitrogen; Thermo Fisher Scientific, Inc.) and incubated for $5 \mathrm{~min}$ at room temperature. The siRNA-lipid complex was diluted into DMEM to achieve a final siRNA concentration of $10 \mathrm{nM}$. Cells were incubated for $24 \mathrm{~h}$ in a $5 \% \mathrm{CO}_{2}$ incubator at $37^{\circ} \mathrm{C}$. For RT-qPCR and western blotting, cell pellets were collected immediately after 24-h transfection. For ELISA and the angiogenesis assay, the medium was exchanged $(1 \mathrm{ml} /$ well $)$ after $24 \mathrm{~h}$ of transfection, and after an additional $48 \mathrm{~h}$, culture supernatants were collected.

Reverse transcription-quantitative PCR (RT-qPCR). Fibroblasts and colorectal cancer cell lines (HT-29, HCT116 and DLD-1) were seeded in 6-well plates with DMEM or RPMI-1640 medium as appropriate for each cell line containing $5 \%$ FBS $\left(1 \times 10^{5}\right.$ cells/well). After overnight incubation, the medium was exchanged and the cells were exposed to the medium with or without $100 \mathrm{ng} / \mathrm{ml} \mathrm{CHI3L1.}$ After $24 \mathrm{~h}$, cell pellets were harvested, and total RNA was extracted from each sample using a QIAcube and RNeasy Plus Mini Kit (Qiagen $\mathrm{GmbH}$ ) according to the manufacturer's protocol. The RNA was reverse transcribed using SuperScript III First-Strand Synthesis SuperMix (Invitrogen; Thermo Fisher Scientific, Inc.) and a T100 Thermal Cycler (Bio-Rad Laboratories, Inc.). The temperature protocol of reverse transcription was as follows: $25^{\circ} \mathrm{C}$ for $10 \mathrm{~min}, 50^{\circ} \mathrm{C}$ for $30 \mathrm{~min}$ and $85^{\circ} \mathrm{C}$ for $5 \mathrm{~min}$. RT-qPCR was performed using TaqMan Gene Expression Assays (cat. no. 4331182; Applied Biosystems; Thermo Fisher Scientific, Inc.) and pre-designed primers for CHI3L1 (Hs01072228_m1), IL-13Ra2 (Hs00152924_m1), $I L-8$ (Hs00174103_m1), VEGFA (Hs00900055_m1) and MCP-1 (Hs00234140_m1) using the CFX Connect Real-Time System (Bio-Rad Laboratories, Inc.). The thermocycling conditions were as follows: Initial denaturation at $95^{\circ} \mathrm{C}$ for $20 \mathrm{sec}$, 
followed by 60 cycles at $95^{\circ} \mathrm{C}$ for $1 \mathrm{sec}$ and $60^{\circ} \mathrm{C}$ for $20 \mathrm{sec}$. GAPDH (Hs99999905_m1) was used as a loading control to normalize mRNA levels and each sample was quantified using the standard curve method (41).

ELISA. Fibroblasts and colorectal cancer cell lines (HT-29, HCT116 and DLD-1) were seeded in 24-well plates with DMEM or RPMI-1640 medium as appropriate for each cell line containing $5 \%$ FBS $\left(2.5 \times 10^{4}\right.$ cells/well $)$. After overnight incubation, the medium was exchanged $(1 \mathrm{ml} / \mathrm{well})$, and the cells were exposed to the medium with or without $100 \mathrm{ng} / \mathrm{ml}$ CHI3L1. After $48 \mathrm{~h}$, culture supernatants were collected and centrifuged at $400 \mathrm{xg}$ for $5 \mathrm{~min}$ at $4^{\circ} \mathrm{C}$ to remove particulates. For siRNA transfection, the medium was exchanged after $24 \mathrm{~h}$ of transfection, and culture supernatants were collected after an additional $48 \mathrm{~h}$. Assays were performed using the Human Chitinase 3-like 1 Quantikine ELISA Kit (cat. no. DC3L10; R\&D Systems, Inc.), Human IL-8-CXCL8 Quantikine ELISA Kit (cat. no. D8000C; R\&D Systems, Inc.) and Human VEGF Quantikine ELISA Kit (cat. no. DVE00; R\&D Systems, Inc.), and the concentration of each protein was measured using a SpectraMax ABS microplate reader (Molecular Devices, LLC) according to the manufacturer's protocol.

Western blotting. The primary antibodies used for western blotting were as follows: Anti-CHI3L1 (dilution, 1:1,000; cat. no. ab77528; Abcam), anti-IL-13R $\alpha 2$ (dilution, 1:1,000; EPR22978-163; cat. no. ab260044; Abcam), and antiGAPDH (dilution, 1:2,000; cat. no. SC-47724; Santa Cruz Biotechnology, Inc.). GAPDH was used as a loading control to normalize protein levels. The secondary antibodies were polyclonal goat anti-rabbit immunoglobulins HRP-conjugated (dilution, 1:2,000; cat. no. P0448; Dako; Agilent Technologies, Inc.) and polyclonal goat anti-mouse immunoglobulins HRP-conjugated (dilution, 1:2,000; cat. no. P0447; Dako; Agilent Technologies, Inc.).

Fibroblasts and colorectal cancer cell lines (HT-29, HCT116 and DLD-1) were seeded at $2 \times 10^{5}$ cells in $10-\mathrm{cm}$ dishes with DMEM or RPMI-1640 medium as appropriate for each cell line containing 5\% FBS and incubated in a $\mathrm{CO}_{2}$ incubator at $37^{\circ} \mathrm{C}$ until cell growth was semi-confluent. Proteins from cell pellets were collected using radioimmunoprecipitation lysis buffer with Protease Inhibitor Single Use Cocktail and Phosphatase Inhibitor Cocktail (all from Thermo Fisher Scientific, Inc.) as previously described (40), and the concentrations of total protein from each sample were measured using a Pierce BCA protein assay kit (Thermo Fisher Scientific, Inc.). Proteins were suspended in SDS sample buffer (90 mM Tris-HCL, 9\% glycerol, 3\% SDS, $150 \mathrm{mM}$ DTT, $0.003 \%$ bromophenol blue, distilled water) and boiled at $90^{\circ} \mathrm{C}$ for $5 \mathrm{~min}$ for denaturation. Proteins $(20 \mu \mathrm{g} /$ lane $)$ were then separated using SDS-PAGE with 10\% Mini-PROTEAN TGX Precast Gels (Bio-Rad Laboratories, Inc.) and transferred onto nitrocellulose membranes (Bio-Rad Laboratories, Inc.). The protein bands on the membrane were blocked with iBind Flex Solution (iBind Flex 5X Buffer, 100X Additive and distilled water; Invitrogen; Thermo Fisher Scientific, Inc.) at room temperature for $10 \mathrm{~min}$. The primary and secondary antibody reactions were then performed using the iBind Flex Western Device (Invitrogen; Thermo Fisher Scientific, Inc.) for $2.5 \mathrm{~h}$ at room temperature according to the manufacturer's protocol. Protein-antibody complex bands were visible on an Amersham Imager 600 (GE Healthcare) using SuperSignal West ECL/Pico/Femto chemiluminescent substrate (Thermo Fisher Scientific, Inc.). The results were semi-quantified by densitometry analysis using ImageJ software version 1.53 (National Institutes of Health).

Angiogenesis assay. To evaluate the direct effects of CHI3L1, IL-8 and VEGFA on vascular endothelial cells, serum-free DMEM containing recombinant CHI3L1, IL-8 or VEGFA was used. The control medium for the addition of recombinant CHI3L1, IL-8 or VEGFA was serum-free DMEM. In addition, to confirm whether secreted CHI3L1 protein produced by CAFs affected angiogenesis, culture supernatants of each cell (NFs, CAFs and HT-29) were used. The control medium for the culture supernatant was DMEM containing 5\% FBS. Culture supernatants were collected as follows: NFs, CAFs and HT-29 were seeded in 24-well plates with medium containing 5\% FBS $\left(2.5 \times 10^{4}\right.$ cells/well). After overnight incubation, the medium was exchanged $(1 \mathrm{ml} /$ well $)$, and the cells were exposed to the medium with or without $\mathrm{mAY}$ or control IgG. After $48 \mathrm{~h}$, culture supernatants were collected and centrifuged at $400 \mathrm{xg}$ for $5 \mathrm{~min}$ at $4^{\circ} \mathrm{C}$ to remove particulates. In the case of transfection in CAFs, after overnight incubation, and 24-h transfection with negative control, CHI3L1, IL-8 or VEGFA siRNA, the medium was exchanged ( $1 \mathrm{ml} /$ well). After an additional $48 \mathrm{~h}$, culture supernatants were collected.

Matrigel Matrix (cat. no. 354230; Corning, Inc.) was added to 96 -well plates $(50 \mu \mathrm{l} / \mathrm{well})$ at $4^{\circ} \mathrm{C}$. The plates were incubated at $37^{\circ} \mathrm{C}$ for $30 \mathrm{~min}$ to solidify the Matrigel. EA.hy 926 cells were trypsinized, counted, resuspended in each medium under the various aforementioned conditions and seeded into Matrigel-coated plates ( $1 \times 10^{4}$ cells/well). After $16 \mathrm{~h}$ of incubation at $37^{\circ} \mathrm{C}$, the plates were observed at a magnification of $x 40$ using the BZ-X710 fluorescence microscope, and the number of endotubes was counted in four fields for each condition.

Cell proliferation assay. Colorectal cancer cell lines (HT-29, HCT116 and DLD-1) were seeded in 96-well plates with DMEM or RPMI-1640 medium as appropriate for each cell line

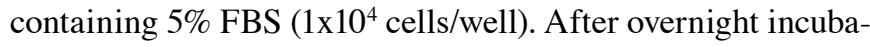
tion, the medium was exchanged and the cells were exposed to the medium with various concentrations $(0-1,000 \mathrm{ng} / \mathrm{ml})$ of CHI3L1 and incubated at $37^{\circ} \mathrm{C}$. After 0,24 and $48 \mathrm{~h}$, medium was exchanged with fresh medium containing premix 4-[3-(4-Iodophenyl)-2-(4-nitro-phenyl)-2H-5-tetrazolio]1,3-benzene sulfonate (WST-1) using a Premix WST-1 Cell Proliferation Assay System (Takara Bio, Inc.) and incubated for $2 \mathrm{~h}$ at $37^{\circ} \mathrm{C}$ in the shade. The absorbance was measured at $450 \mathrm{~nm}$ using a SpectraMax ABS microplate reader (Molecular Devices, LLC) according to the manufacturer's protocol. The absorbance at each timepoint was compared with the absorbance at $0 \mathrm{~h}$ as a standard value for each cancer cell line. Cells without CHI3L1 treatment were used as controls.

Wound healing assay. Colorectal cancer cell lines (HT-29, HCT116 and DLD-1) were cultured in 24-well plates with DMEM or RPMI-1640 medium as appropriate for each cell line containing 10\% FBS until confluency. After the wounds were 
A

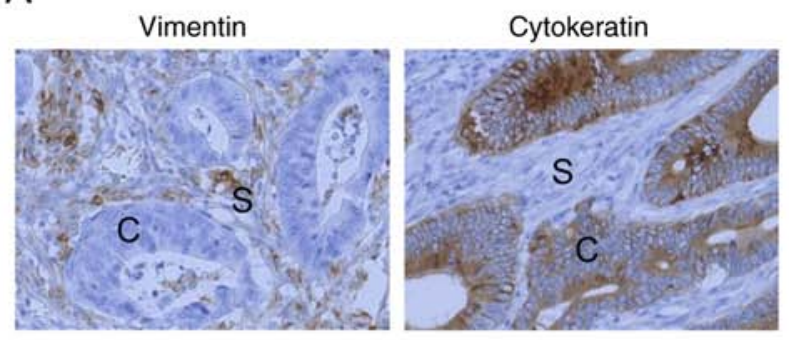

C

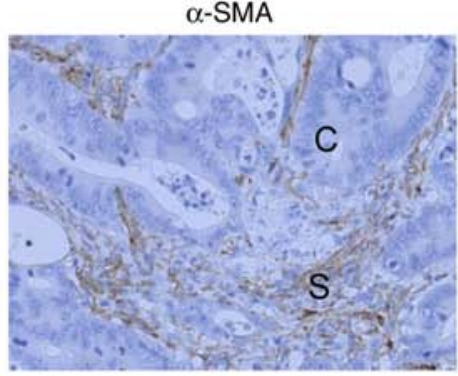

B

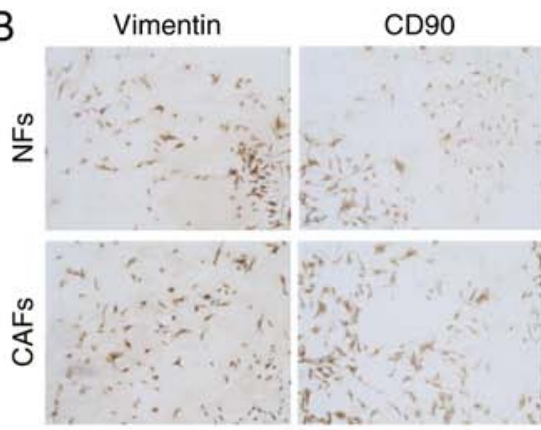

D

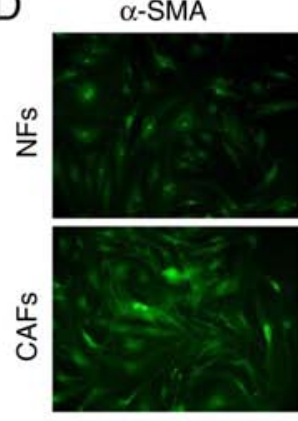

DAPI

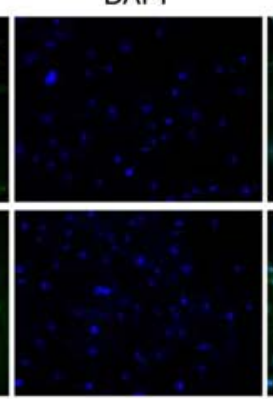

Cytokeratin
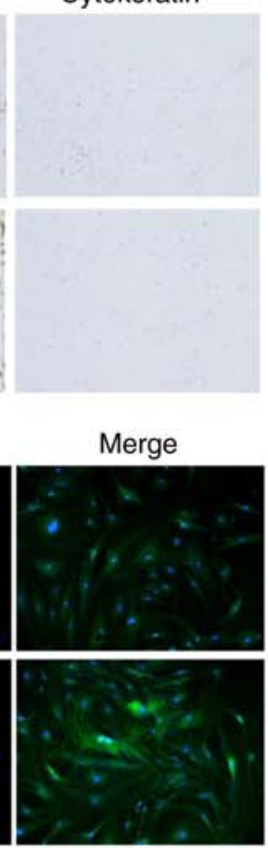

Figure 1. Localization of fibroblasts in cancer tissues and isolated fibroblasts. (A) In cancer tissue from a patient, immunohistochemical staining of vimentin was positive in the stroma (indicated by S) and negative in cancer cells (indicated by C). On the other hand, immunohistochemical staining of cytokeratin was negative in the stroma and positive in cancer cells (magnification, x200). (B) All cultivated cells from the same patient were positive for vimentin and CD90 and negative for cytokeratin (magnification, $x 40$ ). (C) In cancer tissue from the same patient, the stroma (indicated by S) was positive and cancer cells (indicated by $\mathrm{C}$ ) were negative for $\alpha$-SMA immunohistochemical staining (magnification, x200). (D) Fibroblasts from near-cancerous tissues of the same patient (CAFs) were positive for $\alpha$-SMA and fibroblasts from normal tissues of the same patient (NFs) were weakly positive for $\alpha$-SMA (magnification, $\mathrm{x} 200$ ). $\alpha$-SMA, $\alpha$-smooth muscle actin; CAFs, cancer-associated fibroblasts; NFs, normal fibroblasts.

generated by carefully scratching the cells with $200-\mu 1$ pipette tips, the medium was exchanged with fresh medium containing $2 \%$ FBS and the cells were exposed to the medium with or without $100 \mathrm{ng} / \mathrm{ml} \mathrm{CHI3L1}$ at $37^{\circ} \mathrm{C}$. After 0 and $24 \mathrm{~h}$, the plates were observed at a magnification of $\mathrm{x} 40$ using the BZ-X710 fluorescence microscope. The widths of wounds were measured using the BZ-X Analyzer software version 1.4.0.1 and compared with that at $0 \mathrm{~h}$ as a standard value for each cancer cell line. Cells without CHI3L1 treatment were used as controls.

Statistical analysis. Statistical analysis was performed using EZR software (Easy R) version 1.41 (Jichi Medical University Saitama Medical Center, Saitama, Japan). Data are presented as the mean and standard error. Statistical significance was evaluated with unpaired Student's t-tests or one-way ANOVA followed by Tukey's test. All experiments were repeated at least three times. $\mathrm{P}<0.05$ was considered to indicate a statistically significant difference.

\section{Results}

Characterization of isolated and cultured CAFs and NFs. Immunohistochemical analysis of colon adenocarcinoma tissue demonstrated that cancer cells were negative for vimentin, which is a mesenchymal cell marker, and positive for cytokeratin, which is an epithelial cell marker $(5,17,18,42)$. On the other hand, stromal cells were positive for vimentin and negative for cytokeratin (Fig. 1A). Furthermore, to confirm that the isolated and cultured cells were fibroblasts, immunostaining for vimentin, CD90 and cytokeratin was performed $(5,17,18,42,43)$. Both cells from near-cancerous colon tissues (CAFs) and those from normal colon tissues (NFs) were positive for vimentin and CD90 and negative for cytokeratin, indicating that all of these cells were fibroblasts (Fig. 1B). In addition, to confirm the myofibroblast characteristics of CAFs, which express $\alpha$-SMA, immunohistochemical and cell immunofluorescence staining of $\alpha$-SMA was also performed (6). In the immunohistochemical analysis, stromal cells were positive for $\alpha$-SMA and cancer cells were negative for $\alpha$-SMA (Fig. 1C). Immunofluorescence staining indicated that all fibroblasts were positive for $\alpha$-SMA; however, $\alpha$-SMA expression was stronger in fibroblasts from near-cancerous tissues (CAFs) and weaker in fibroblasts from normal tissues (NFs) (Fig. 1D). Therefore, fibroblasts isolated from nearcancerous tissues were referred to as CAFs, and fibroblasts isolated from normal tissues were referred to as NFs.

Secretion of CHI3L1 from CAFs, NFs and cancer cell lines. First, analysis of cytokines secreted from each cell line using a cytokine array of cell culture supernatants demonstrated that CAFs secreted more CHI3L1 and IL-8 than NFs (Fig. 2A). Subsequently, to investigate the origin of CHI3L1 in the cancer microenvironment,immunohistochemistry, RT-qPCR, western blotting and ELISA were performed to evaluate CHI3L1 expression in, and secretion from, fibroblasts and cancer cells or three colorectal cancer cell lines. Immunohistochemistry demonstrated that CHI3L1 was weakly expressed in cancer cells and strongly expressed in portions of the stroma (Fig. 2B). RT-qPCR revealed that $C H I 3 L 1$ mRNA expression was $>4$ times higher in CAFs than in NFs but was less than 
A

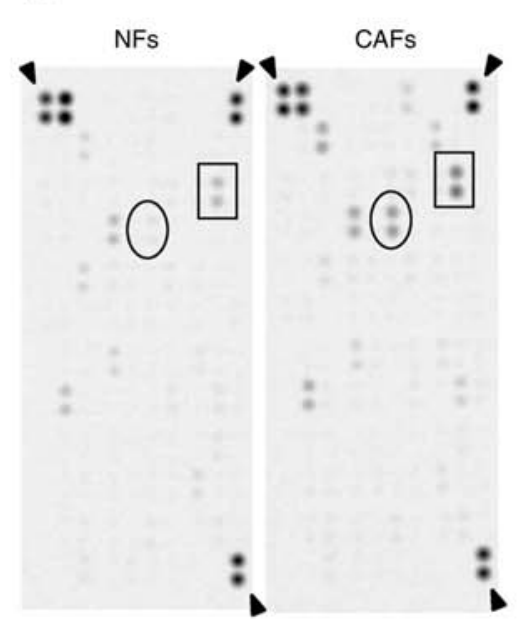

B

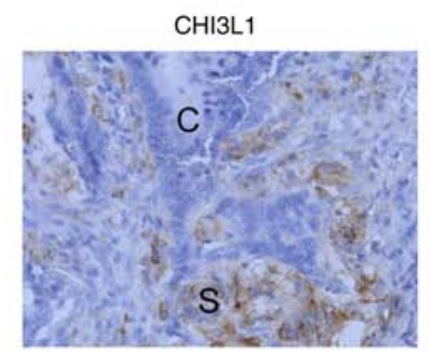

D

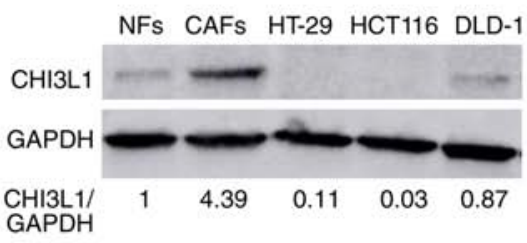

C

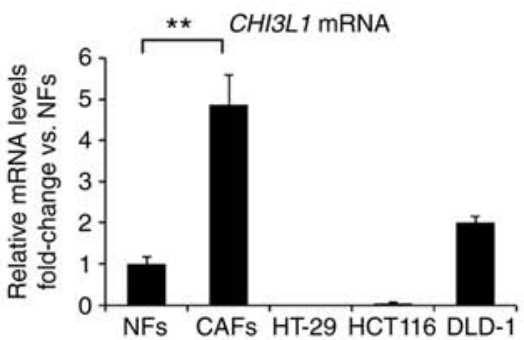

E

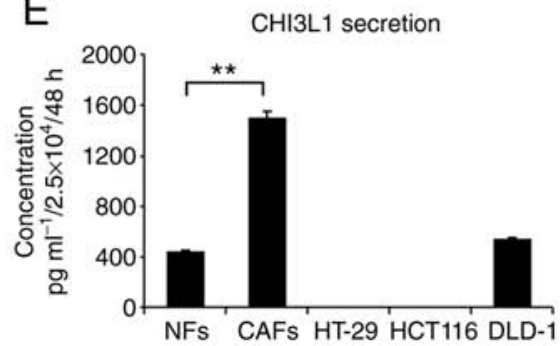

Figure 2. Expression and secretion of CHI3L1 in fibroblasts and colorectal cancer cells. (A) A cytokine array of the cell culture supernatant revealed that CAFs secreted more CHI3L1 and IL-8 than NFs. The rectangles and circles represent CHI3L1 and IL-8, respectively. The two spots in three of the corners (arrowheads) are positive controls. (B) Immunohistochemical staining demonstrated that in cancer tissues, CHI3L1 was localized mainly in the stroma (indicated by S), with no obvious expression in cancer cells (indicated by C; magnification, x200). (C) Reverse transcription-quantitative PCR revealed that CHI3L1 mRNA expression in CAFs was higher than that in NFs and three cancer cell lines. (D) Western blotting also demonstrated that CAFs produced more CHI3L1 than NFs and cancer cells. (E) ELISA of the cell culture supernatants revealed that CAFs secreted more CHI3L1 than NFs and cancer cells. Data are presented as the mean \pm SEM. ${ }^{* *} \mathrm{P}<0.01$. The relative mRNA expression levels of $C H I 3 L 1$ were normalized to GAPDH expression in each sample. CAFs, cancer-associated fibroblasts; CHI3L1, chitinase 3-like 1; NFs, normal fibroblasts.
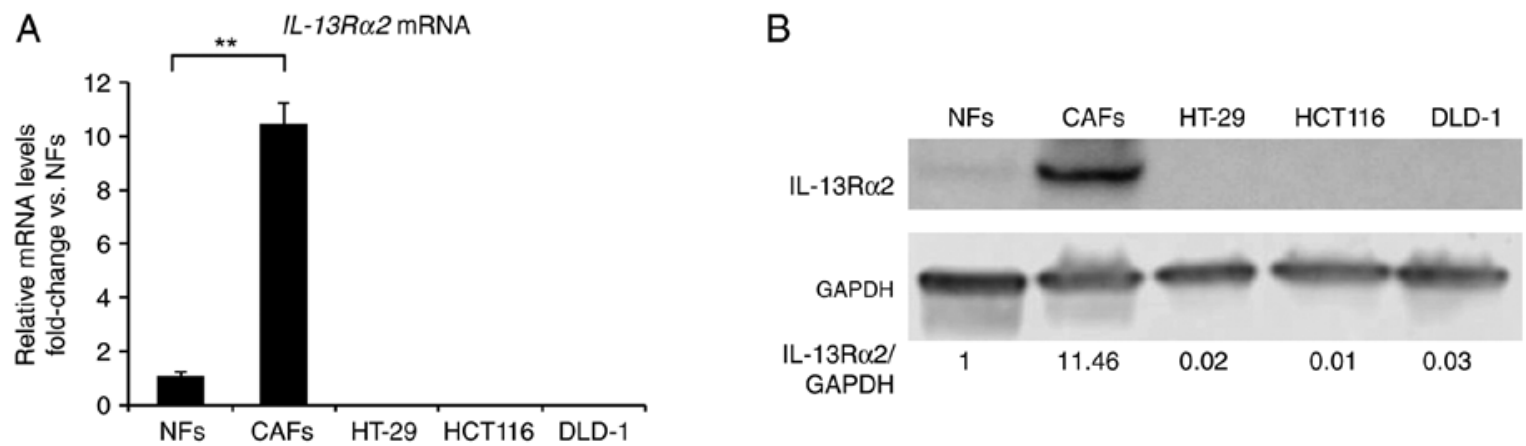

Figure 3. Expression levels of IL-13a2 (a receptor for chitinase 3-like 1) in fibroblasts and colorectal cancer cells. (A) Reverse transcription-quantitative PCR revealed that both CAFs and NFs expressed $I L-13 R \alpha 2$, whereas cancer cell lines expressed little $I L-13 R \alpha 2$. (B) Western blotting also demonstrated that CAFs expressed higher levels of IL-13 $\alpha 2$ than NFs and cancer cells. Data are presented as the mean \pm SEM. ${ }^{* *} \mathrm{P}<0.01$. The relative mRNA expression levels of $I L-13 \alpha 2$ were normalized to GAPDH expression in each sample. CAFs, cancer-associated fibroblasts; IL-13R $\alpha 2$, interleukin-13 receptor $\alpha 2$; NFs, normal fibroblasts.

half of that in CAFs in DLD-1 cells; HT-29 and HCT116 cells rarely expressed CHI3L1 (Fig. 2C). Furthermore, western blotting of CHI3L1 demonstrated that CAFs expressed higher levels of CHI3L1 compared with NFs and colorectal cancer cell lines (Fig. 2D). ELISA using the culture supernatants yielded similar results to those of RT-qPCR and western blotting. CAFs secreted higher levels of CHI3L1, whereas NFs and DLD-1 cells secreted lower levels of CHI3L1, and HT-29 and HCT116 cells secreted little CHI3L1 (Fig. 2E). These results indicated that CAFs were the main origin of $\mathrm{CHI} 3 \mathrm{~L} 1$ secretion in the colorectal cancer microenvironment.

CAFs express the CHI3L1 receptor $I L-13 R \alpha 2$. A number of CHI3L1 receptors have not yet been identified; however, IL-13R $\alpha 2$ has previously been reported as a CHI3L1 receptor (44-47). Therefore, RT-qPCR and western blotting were performed to evaluate IL-13R $\alpha 2$ expression in fibroblasts and colorectal cancer cell lines. RT-qPCR demonstrated that both CAFs and NFs expressed $I L-13 R \alpha 2$. In particular, expression in CAFs was 10 times higher than that in NFs, whereas expression was rarely observed in the three cancer cell lines (Fig. 3A). The results of western blotting were similar to those of RT-qPCR (Fig. 3B).

Effects of CHI3L1 on IL-8 and VEGFA levels in CAFs. IL-8 and VEGFA are angiogenicfactors and it is possible that CHI3L1 is involved in their expression and secretion $(31,33,38,39)$. Therefore, RT-qPCR and ELISA were conducted to evaluate the effect of CHI3L1 on IL-8 and VEGFA levels. First, the effect of various concentrations of CHI3L1 (1-1,000 ng/ml) 


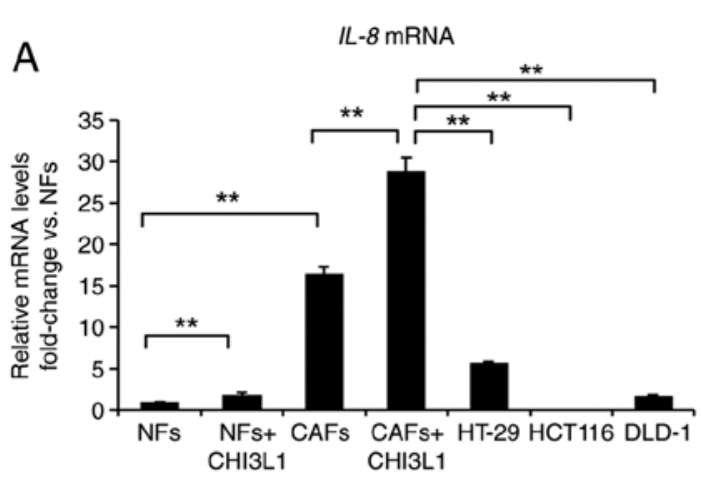

C
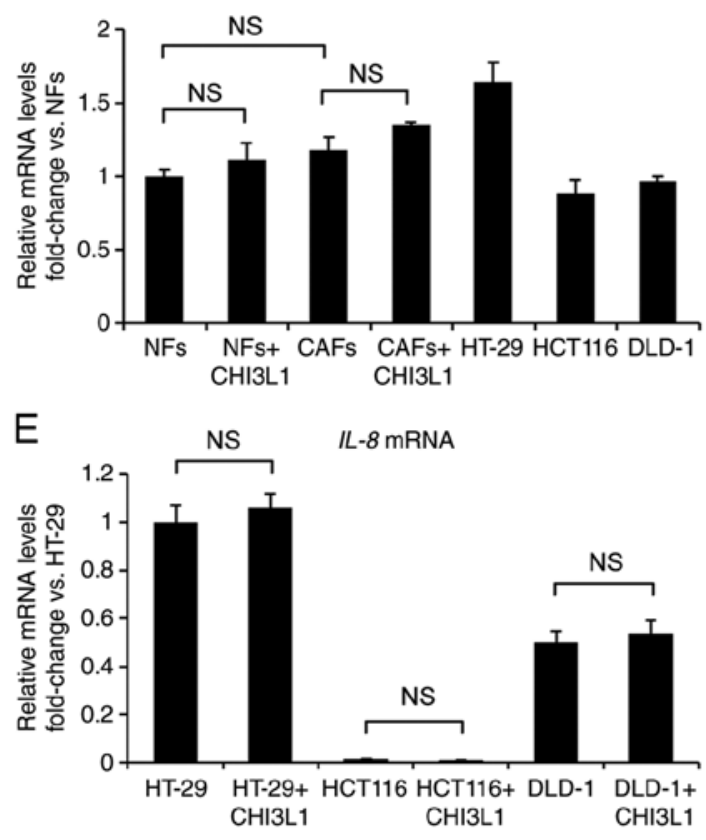

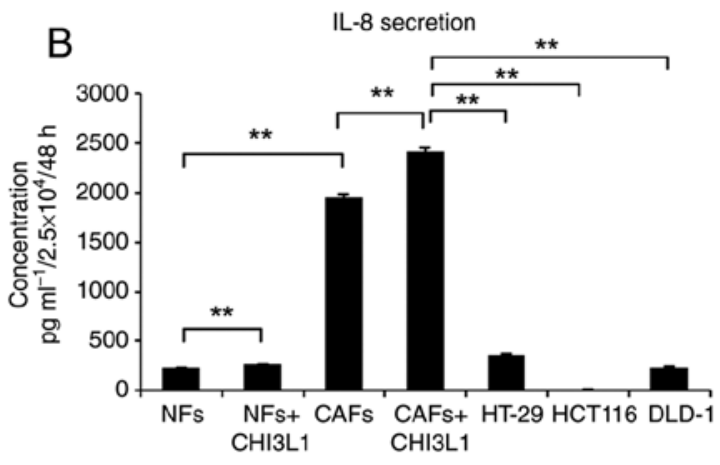

D VEGFA secretion

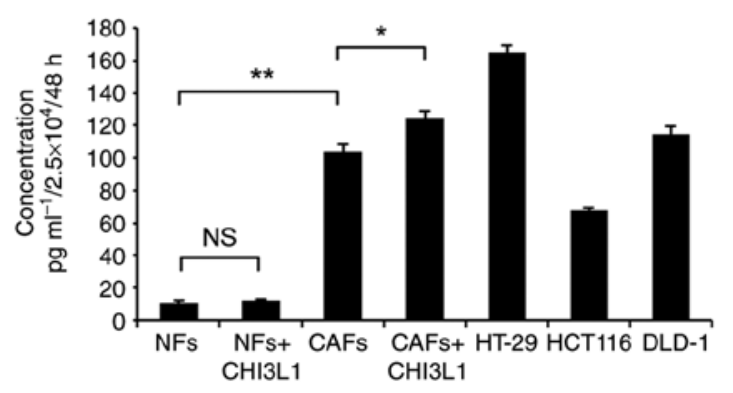

$\mathrm{F}$

VEGFA MRNA

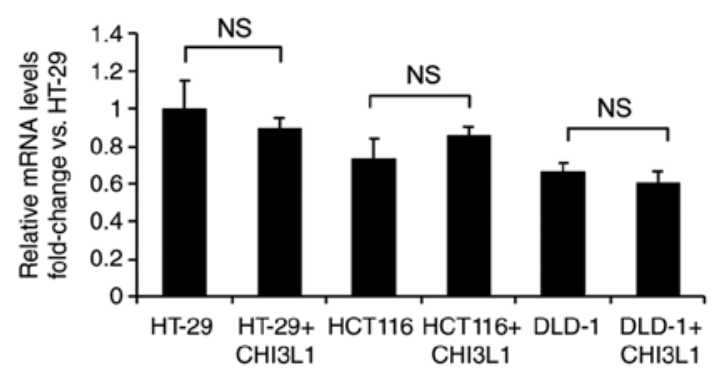

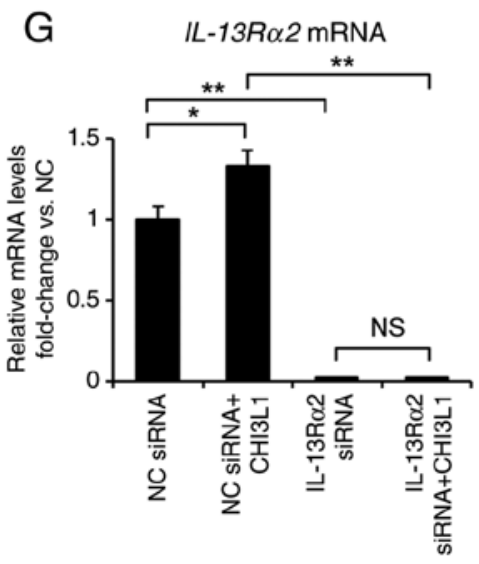
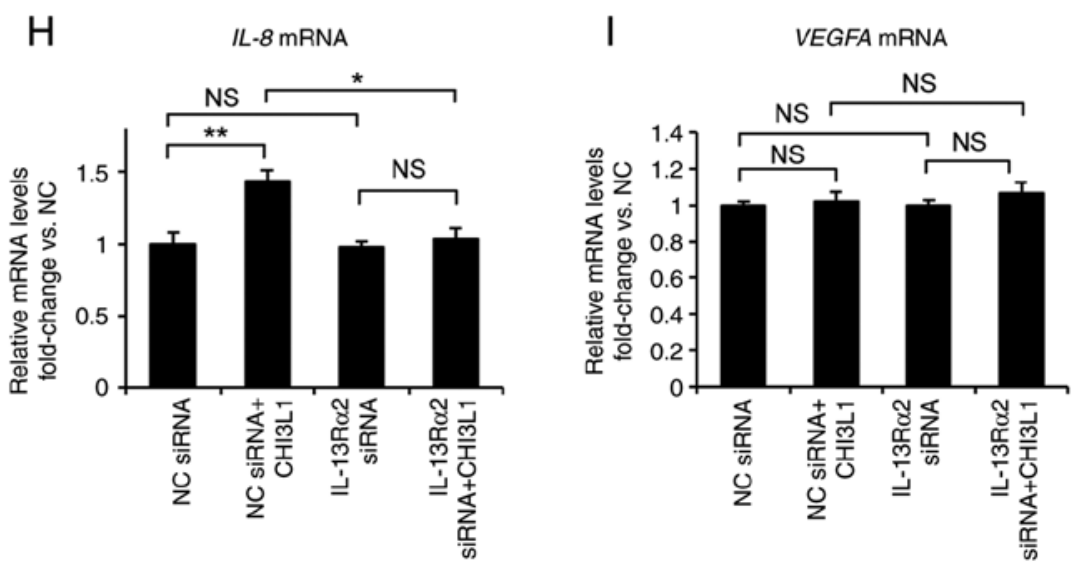

Figure 4. Changes in IL-8 and VEGFA following the addition of $100 \mathrm{ng} / \mathrm{ml} \mathrm{CHI3L1.} \mathrm{(A)} \mathrm{RT-qPCR} \mathrm{indicated} \mathrm{that} \mathrm{IL-8} \mathrm{mRNA} \mathrm{expression} \mathrm{was} \mathrm{higher} \mathrm{in} \mathrm{CAFs}$ than in NFs and cancer cells and that 24-h treatment with $100 \mathrm{ng} / \mathrm{ml} \mathrm{CHI3L1} \mathrm{increased} \mathrm{IL-8} \mathrm{expression} \mathrm{in} \mathrm{CAFs.} \mathrm{(B)} \mathrm{ELISA} \mathrm{of} \mathrm{the} \mathrm{cell} \mathrm{culture} \mathrm{supernatants}$ revealed that CAFs secreted more CHI3L1 than NFs and cancer cells, and that 48-h treatment with $100 \mathrm{ng} / \mathrm{ml} \mathrm{CHI3L1} \mathrm{further} \mathrm{increased} \mathrm{IL-8} \mathrm{secretion} \mathrm{from}$ CAFs. (C) RT-qPCR demonstrated that VEGFA mRNA expression was slightly stronger in CAFs than in NFs, although the difference was not significant. Treatment of CAFs with CHI3L1 did not affect VEGFA expression. (D) In contrast to RT-qPCR, ELISA of the cell culture supernatants demonstrated significant differences in VEGFA secretion between untreated CAFs and CAFs treated with $100 \mathrm{ng} / \mathrm{ml} \mathrm{CHI3L1;} \mathrm{however,} \mathrm{VEGFA} \mathrm{secretion} \mathrm{from} \mathrm{CAFs} \mathrm{was}$ not particularly high compared with that from cancer cell lines. (E) RT-qPCR revealed no significant changes in $I L-8$ mRNA expression in the three cancer cell lines, between groups treated with and without $100 \mathrm{ng} / \mathrm{ml} \mathrm{CHI3L1.} \mathrm{(F)} \mathrm{RT-qPCR} \mathrm{revealed} \mathrm{no} \mathrm{significant} \mathrm{changes} \mathrm{in} \mathrm{VEGFA} \mathrm{mRNA} \mathrm{expression} \mathrm{in} \mathrm{the}$ three cancer cells, between groups treated with and without $100 \mathrm{ng} / \mathrm{ml} \mathrm{CHI3L1.(G)} \mathrm{RT-qPCR} \mathrm{demonstrated} \mathrm{that} I L-13 R \alpha 2$ expression in CAFs was suppressed after transfection with IL-13R $\alpha 2$ siRNA. (H) RT-qPCR indicated that IL-13R $\alpha 2$ knockdown suppressed the enhanced $I L-8$ mRNA expression induced by CHI3L1 treatment in CAFs. (I) RT-qPCR revealed that IL-13R 22 knockdown and the addition of CHI3L1 did not change VEGFA mRNA expression in CAFs. Data are presented as the mean $\pm \mathrm{SEM}$. ${ }^{*} \mathrm{P}<0.05,{ }^{* *} \mathrm{P}<0.01$. The relative mRNA expression levels of $I L-8, V E G F A$ and $I L-13 R \alpha 2$ were normalized to GAPDH expression in each sample. CAFs, cancer-associated fibroblasts; CHI3L1, chitinase 3-like 1; IL-13R $\alpha 2$, interleukin-13 receptor $\alpha 2$; NC, negative control; NFs, normal fibroblasts; NS, not significant; RT-qPCR, reverse transcription-quantitative PCR; si/siRNA, small interfering RNA; VEGFA, vascular endothelial growth factor-A. 

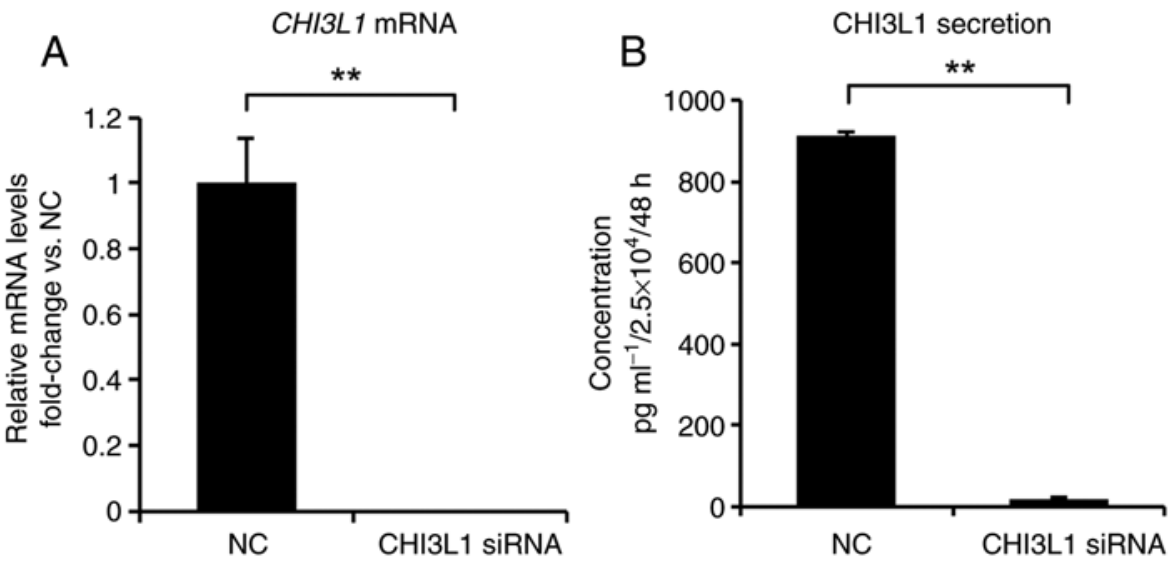

C
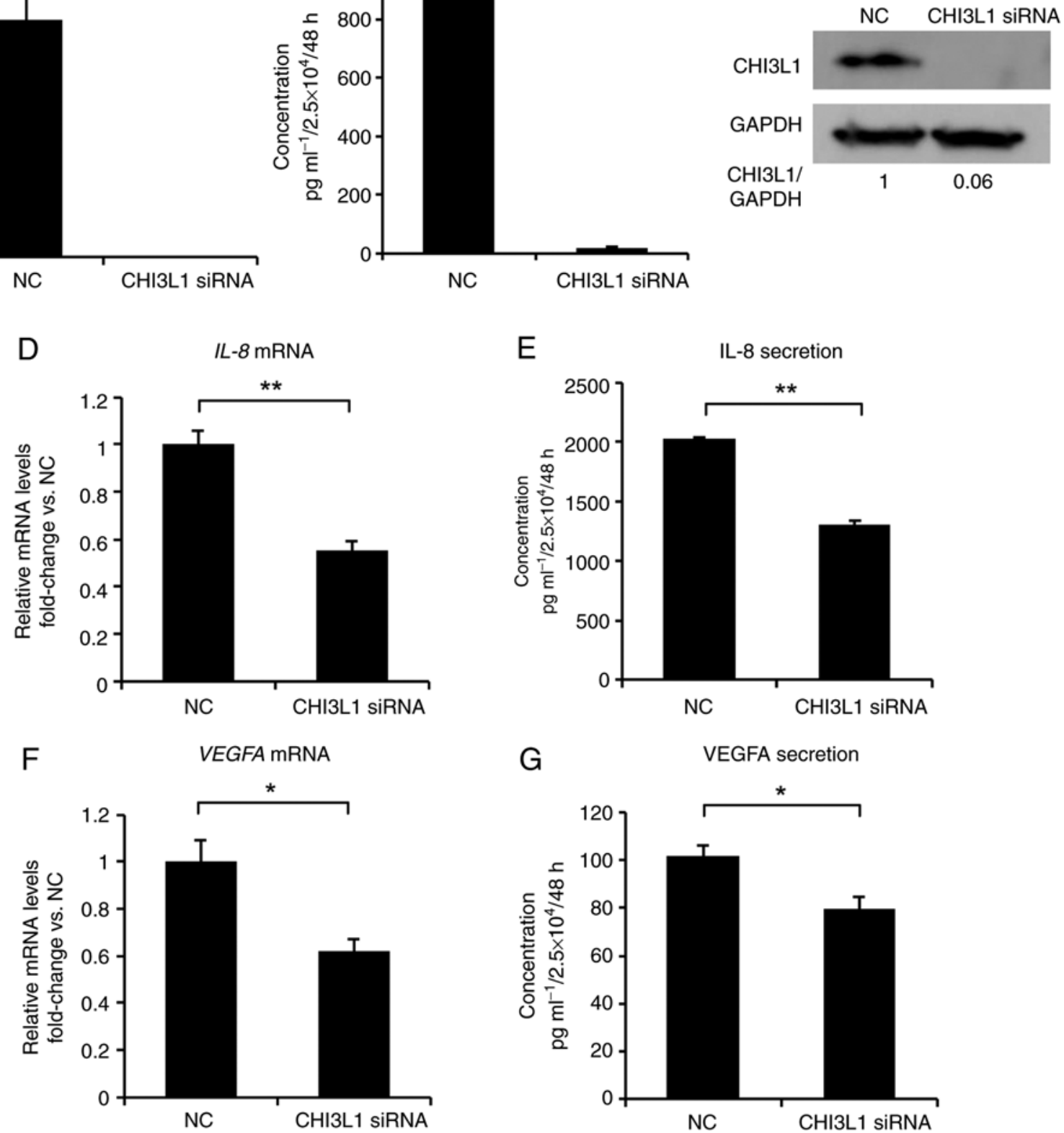

Figure 5. Changes in IL-8 and VEGFA after CHI3L1 knockdown in CAFs. (A) RT-qPCR indicated that CHI3L1 mRNA expression in CAFs was suppressed by transfection with CHI3L1 siRNA. (B) ELISA of the cell culture supernatants demonstrated that CHI3L1 secretion in CAFs was suppressed by transfection with CHI3L1 siRNA. (C) Western blotting revealed that CHI3L1 protein expression in CAFs was suppressed after transfection with CHI3L1 siRNA. (D) RT-qPCR indicated that $I L-8$ mRNA expression in CAFs was suppressed by transfection with CHI3L1 siRNA. (E) ELISA of the cell culture supernatants demonstrated that IL-8 secretion in CAFs was suppressed by transfection with CHI3L1 siRNA. (F) RT-qPCR revealed that VEGFA mRNA expression in CAFs was suppressed by transfection with CHI3L1 siRNA. (G) ELISA of the cell culture supernatants indicated that VEGFA secretion in CAFs was suppressed by transfection with CHI3L1 siRNA. Data are presented as the mean $\pm \mathrm{SEM}$. ${ }^{*} \mathrm{P}<0.05,{ }^{* * *} \mathrm{P}<0.01$. The relative mRNA expression levels of $C H I 3 L 1, I L-8$ and VEGFA were normalized to GAPDH expression in each sample. CAFs, cancer-associated fibroblasts; CHI3L1, chitinase 3-like 1; NC, negative control; RT-qPCR, reverse transcription-quantitative PCR; si/siRNA, small interfering RNA; VEGFA, vascular endothelial growth factor-A.

on $I L-8 / V E G F A$ expression was assessed by RT-qPCR using CAFs without CHI3L1 treatment as a control (Fig. S1). $I L-8$ mRNA expression in CAFs was markedly enhanced after treatment with CHI3L1 at concentrations $\geq 10 \mathrm{ng} / \mathrm{ml}$, while $V E G F A$ mRNA expression in CAFs was not significantly enhanced except at concentrations of $1,000 \mathrm{ng} / \mathrm{ml}$. Based on these results and existing reports $(11,32,33,38,39), \mathrm{CHI} 3 \mathrm{~L} 1$ at a concentration of $100 \mathrm{ng} / \mathrm{ml}$ was used in subsequent experiments.
Subsequently, after $100 \mathrm{ng} / \mathrm{ml} \mathrm{CHI3L1}$ treatment, the $I L-8$ and VEGFA mRNA levels in fibroblasts and colorectal cancer cell lines were measured by RT-qPCR at $24 \mathrm{~h}$ and the secreted protein levels in the cell culture supernatants were measured by ELISA at $48 \mathrm{~h}$.

RT-qPCR revealed that $I L-8$ expression in CAFs was $\sim 16$ times higher than that in NFs, and was also markedly higher than that in the three cancer cell lines (Fig. 4A). Furthermore, 
A

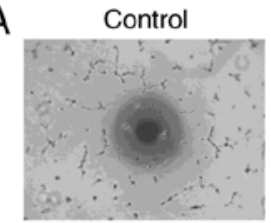

IL-8 $100 \mathrm{ng} / \mathrm{ml}$

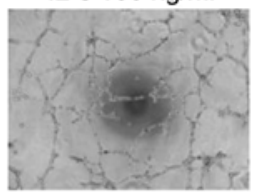

CHI3L1 $100 \mathrm{ng} / \mathrm{ml}$
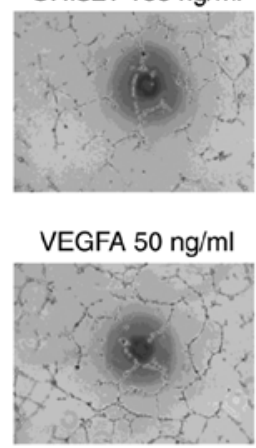

C

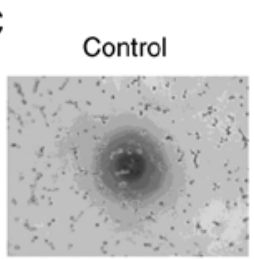

Cancer cell CM

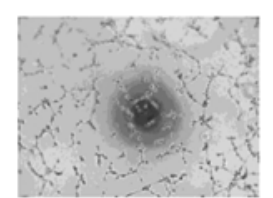

CM from NC siRNAtransfected CAFs

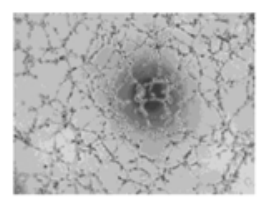

CM from CHI3L1 siRNAtransfected CAFs

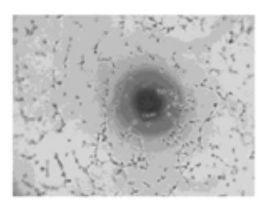

D

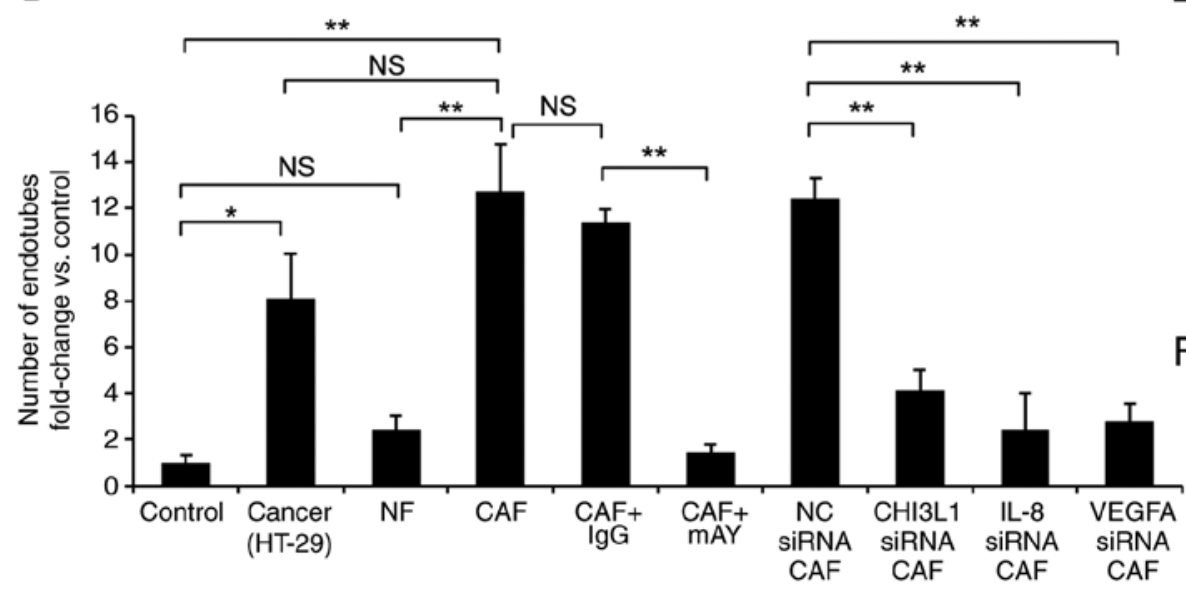

B

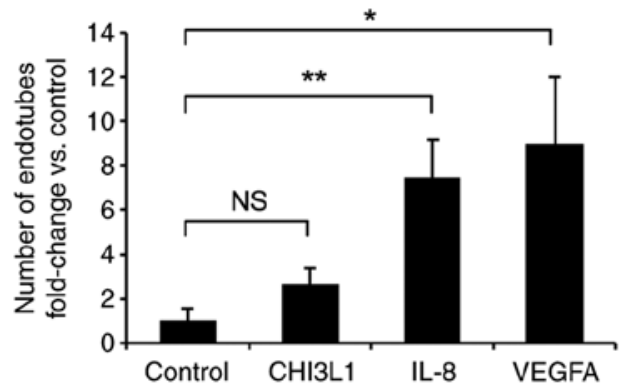

CAF CM

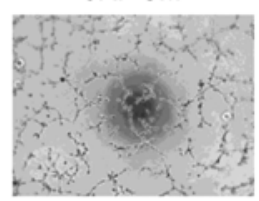

CM from IL-8 siRNAtransfected CAFs
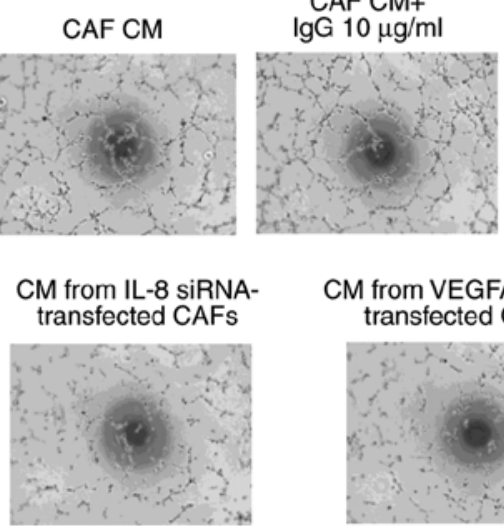

CAF $\mathrm{CM}+$ $\mathrm{mAY} 10 \mu \mathrm{g} / \mathrm{m}$

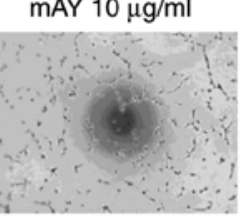

CM from VEGFA siRNAtransfected CAFs

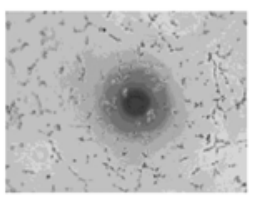

E

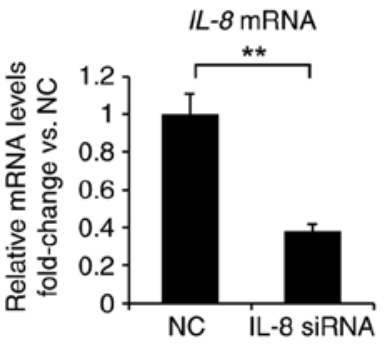

$F$

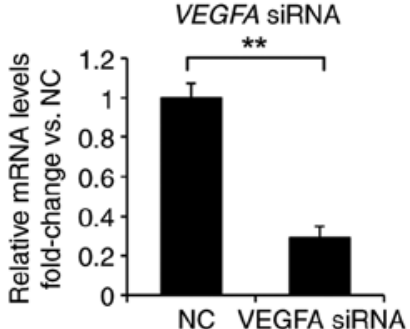

Figure 6. Effects of CHI3L1 on tube formation in vascular endothelial cells. (A) EA.hy926 cells were cultured in serum-free DMEM, serum-free DMEM with $100 \mathrm{ng} / \mathrm{ml} \mathrm{CHI3L1,} \mathrm{serum-free} \mathrm{DMEM} \mathrm{with} 100 \mathrm{ng} / \mathrm{ml} \mathrm{IL-8}$ and serum-free DMEM with $50 \mathrm{ng} / \mathrm{ml}$ VEGFA. The cells incubated with serum-free DMEM alone were used as a control (magnification, x40). (B) IL-8 and VEGFA increased tube formation by EA.hy926 cells, and CHI3L1 tended to increase tube formation by EA.hy926 cells, although no significant difference was observed. (C) EA.hy926 cells were cultured in DMEM containing 5\% FBS, conditioned medium from cancer cells (HT-29), NF or CAF cultures, conditioned medium from CAFs treated with control IgG or mAY at $10 \mu \mathrm{g} / \mathrm{ml}$, and conditioned medium from CAFs transfected with negative control, CHI3L1, IL-8 or VEGFA siRNA. The cells incubated only with DMEM containing 5\% FBS were used as controls (magnification, $\mathrm{x} 40$ ). (D) CM from CAFs increased tube formation by EA.hy 926 cells compared with control CM and CM from NFs. The addition of mAY or transfection of CAFs with CHI3L1, IL-8 or VEGFA siRNA suppressed the effects of CAF CM on tube formation. (E) RT-qPCR demonstrated that $I L-8$ mRNA expression in CAFs was suppressed by transfection with IL-8 siRNA. (F) RT-qPCR demonstrated that $V E G F A$ mRNA expression in CAFs was suppressed by transfection with VEGFA siRNA. Data are presented as the mean $\pm \mathrm{SEM}$. ${ }^{*} \mathrm{P}<0.05,{ }^{* *} \mathrm{P}<0.01$. The relative mRNA expression levels of $I L-8$ and VEGFA were normalized to GAPDH expression in each sample. CAFs, cancer-associated fibroblasts; CHI3L1, chitinase 3-like 1; CM, conditioned medium; mAY, human CHI3L1 neutralizing antibody; NC, negative control; NFs, normal fibroblasts; NS, not significant; RT-qPCR, reverse transcription-quantitative PCR; si/siRNA, small interfering RNA; VEGFA, vascular endothelial growth factor-A.

treatment with CHI3L1 increased $I L-8$ expression in CAFs. ELISA also demonstrated that CAFs secreted more IL-8 than NFs and cancer cell lines, and the addition of CHI3L1 to CAFs further increased IL-8 secretion from CAFs (Fig. 4B).
RT-qPCR demonstrated that VEGFA expression was higher in CAFs than in NFs, although this difference was not significant. Although VEGFA expression in the three cancer cell lines differed depending on the cell line, there were no 


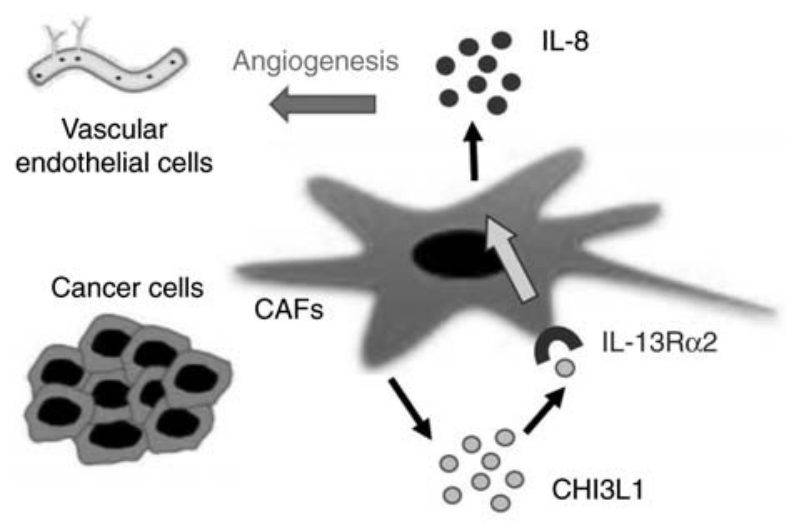

Figure 7. Mechanisms through which CHI3L1 promotes tumor angiogenesis in colorectal cancer. CHI3L1, which is mainly secreted from CAFs, acts on CAFs themselves to increase the secretion of IL- 8 from CAFs, which then promotes tumor angiogenesis in colorectal cancer. CAFs, cancer-associated fibroblasts; CHI3L1, chitinase 3-like 1; IL-13R $\alpha 2$, interleukin-13 receptor $\alpha 2$.

clear differences compared with in CAFs. Furthermore, the addition of CHI3L1 to CAFs did not cause significant changes (Fig. 4C). ELISA demonstrated significant differences between CAFs and NFs, and between untreated CAFs and CHI3L1treated CAFs. However, VEGFA secretion from CAFs was not particularly high compared with that from the cancer cell lines (Fig. 4D). In the three cancer cell lines, RT-qPCR revealed no significant changes in the expression levels of IL-8 or VEGFA between groups treated with and without CHI3L1 in all cell lines (Fig. 4E and F).

To confirm the relationship between CHI3L1 and IL-13R $\alpha 2$, a receptor for CHI3L1, the present study also evaluated $I L-8$ and VEGFA expression after CHI3L1 treatment and knockdown of IL-13R $\alpha 2$ in CAFs. Compared with the negative control siRNA, transfection with IL-13R $\alpha 2$ siRNA significantly downregulated $I L-13 R \alpha 2$ expression in CAFs, as demonstrated by RT-qPCR (Fig. 4G). IL-13R $\alpha 2$ siRNA also suppressed the enhanced IL- 8 expression induced by the addition of CHI3L1 to CAFs (Fig. 4H). On the other hand, IL-13R $\alpha 2$ siRNA did not significantly affect VEGFA expression in CAFs (Fig. 4I).

According to a previous report (33), MCP-1 is related to CHI3L1. The present study revealed that it is secreted from CAFs and NFs using a cytokine array; however, RT-qPCR revealed a decrease in $M C P-1$ expression after the addition of $100 \mathrm{ng} / \mathrm{ml} \mathrm{CHI3L1} \mathrm{in} \mathrm{CAFs} \mathrm{(Fig.} \mathrm{S2).} \mathrm{Furthermore,} \mathrm{although}$ some reports have demonstrated that CHI3L1 has effects other than angiogenesis $(11,32,33,38)$, in the present study, there was no CHI3L1 dose-dependent effect on proliferation and no significant effect on migration in colorectal cancer cell lines (Fig. S3).

Changes in IL-8 and VEGFA expression after CHI3LI knockdown in CAFs. RT-qPCR, western blotting and ELISA were performed to evaluate changes in the expression and secretion of IL-8 and VEGFA in CAFs transfected with CHI3L1 siRNA. Compared with the negative control siRNA, transfection with CHI3L1 siRNA significantly downregulated CHI3L1 expression and secretion in CAFs (Fig. 5A-C). Furthermore, RT-qPCR and ELISA demonstrated that transfection with CHI3L1 siRNA also significantly suppressed IL-8 expression and secretion in CAFs (Fig. 5D and E). Furthermore, RT-qPCR and ELISA showed that transfection also significantly suppressed VEGFA expression and secretion in CAFs (Fig. 5F and G).

Effects of CHI3L1 on tube formation by vascular endothelial cells. Matrigel angiogenesis assays were subsequently performed to evaluate the effects of CHI3L1 on tube formation in EA.hy926 vascular endothelial cells using either recombinant addition or cell culture supernatants.

First, to evaluate the direct effects of CHI3L1, IL-8 and VEGFA on vascular endothelial cells, tube formation was compared between control medium (serum-free DMEM) and medium containing recombinant $\mathrm{CHI} 3 \mathrm{L1}$, IL-8 or VEGFA (Fig. 6A and B). IL-8 and VEGFA, which are angiogenic factors (48), significantly increased tube formation of EA.hy926 cells compared with the control when applied at concentrations of 100 and $50 \mathrm{ng} / \mathrm{ml}$, respectively. In addition, CHI3L1 tended to increase tube formation of EA.hy926 cells compared with the control when applied at a concentration of $100 \mathrm{ng} / \mathrm{ml}$, although the difference was not significant.

Subsequently, to confirm whether secreted CHI3L1 protein produced by CAFs affected angiogenesis, tube formation was compared after treatment with control medium (DMEM containing 5\% FBS), conditioned medium from cancer cells (HT-29), NF or CAF cultures, conditioned medium from CAFs treated with control IgG or mAY at $10 \mu \mathrm{g} / \mathrm{ml}$, and conditioned medium from CAFs transfected with negative control, CHI3L1, IL-8 or VEGFA siRNA (Fig. 6C and D). CAF supernatants significantly increased tube formation of EA.hy926 cells compared with control and NF supernatants. Furthermore, CAF supernatants tended to increase tube formation compared with HT-29 supernatants, although the difference was not significant. The addition of control IgG had no inhibitory effects on tube formation by CAF supernatants, but the addition of mAY significantly inhibited tube formation by CAF supernatants compared with control IgG. Furthermore, tube formation was significantly suppressed by conditioned medium from CAFs transfected with CHI3L1, IL-8 or VEGFA siRNA compared with that from CAFs transfected with negative control siRNA. For reference, compared with the negative control siRNA, transfection with IL-8 or VEGFA siRNA significantly suppressed IL-8 or VEGFA expression, respectively, in CAFs (Fig. 6E and F).

\section{Discussion}

CAFs have been demonstrated to have important roles in the cancer microenvironment, and the involvement of cytokines and tumor growth factors secreted by CAFs is being actively investigated $(3-5,7)$. The present study demonstrated that CHI3L1 was mainly secreted from CAFs in the cancer microenvironment and was involved in tumor angiogenesis via IL-8 secretion. Previous reports have suggested that CHI3L1 is expressed by and secreted from cancer cells (31-33). Furthermore, CHI3L1 has been reported to serve a role in cancer progression by CAFs; however, this mechanism has only been investigated in the context of immune cells or exosomes, not cytokines $(11,35)$. Accordingly, the present study focused on cytokines secreted 
from CAFs and demonstrated that CAFs, not cancer cells, mainly secreted CHI3L1 and IL-8. However, CAFs are not the only origin of $\mathrm{CHI} 3 \mathrm{Ll}$ and angiogenic factors. As shown in previous reports $(32,33)$ and the present study, some colorectal cancer cell lines secrete CHI3L1, IL-8 and VEGFA, suggesting that both CAFs and cancer cells may be potential origins of CHI3L1 and angiogenic factors. Furthermore, because CAFs may be derived from several cell types, the secretion of CHI3L1 and angiogenic factors from CAFs of different individuals may also differ (4). However, the present results suggested that CHI3L1 and angiogenic factors secreted from CAFs may have roles in the cancer microenvironment.

In the present study, to clarify the mechanisms of action of CHI3L1 secreted from CAFs in the cancer microenvironment, CHI3L1 receptor expression in various cell types was also evaluated. Although the details of CHI3L1 receptors have not been fully elucidated, a number of previous studies have reported that IL-13R $\alpha 2$ is a CHI3L1 receptor (44-47). IL-13R $\alpha 2$ expression is upregulated in melanoma, head and neck cancer, and glioma, as well as other types of malignant tumors (49-51). In colorectal cancer, high IL-13R $\alpha 2$ expression in cancer cells is associated with a poor prognosis (52), although individual differences are also observed. In the present study, expression was observed in fibroblasts, particularly CAFs, but weak expression was observed in colon cancer cell lines. In addition, IL-8 expression and secretion were affected by CHI3L1 treatment in CAFs, but not in cancer cells. Furthermore, IL-13R $\alpha 2$ knockdown suppressed the enhanced IL-8 expression induced by $\mathrm{CHI} 3 \mathrm{~L} 1$ treatment in CAFs, suggesting that this receptor may be involved in CHI3L1-dependent IL-8 production by CAFs. CHI3L1 has also been reported to act directly on cancer cells and to be involved in cancer progression, including proliferation and migration $(33,38,53)$. Therefore, CHI3L1 receptors other than IL-13R $\alpha 2$ may be involved in mediating the effects of CHI3L1 in the cancer microenvironment. Indeed, CD44v3 and transmembrane protein 219 have been reported to act as CHI3L1 receptors $(26,45,53)$. Overall, the results of the present study indicated that $\mathrm{CHI} 3 \mathrm{~L} 1$ affected cancer progression by acting on CAFs, rather than through direct effects on cancer cells.

CHI3L1 affects angiogenesis (31-33), an important mechanism that supports cancer progression by supplying nutrients and oxygen. Additionally, anti-angiogenic drugs have been demonstrated to serve important roles in colorectal cancer treatment $(1,54)$. VEGFA, IL-8, monocyte chemotactic protein-1, bFGF, platelet-derived growth factor, hepatocyte growth factor and epidermal growth factor are angiogenic factors, and our previous studies revealed that IL-6-dependent VEGFA secretion from CAFs promoted cancer angiogenesis $(7,55)$. Furthermore, CHI3L1 may be related to the angiogenic functions of IL-8, VEGFA and MCP-1 $(31,33,38,39)$. The present study focused mainly on IL-8 signaling by performing cytokine array analysis. Changes in IL-8 secretion were observed after CHI3L1 addition or CHI3L1 knockdown in CAFs, suggesting that IL-8 secretion from CAFs may be regulated by CHI3L1 and that CHI3L1 may be related to IL-8-mediated angiogenesis. The involvement of VEGFA was not clarified in the present study because not all of the results showed significant differences. A previous report has suggested that VEGFA is involved in
CHI3L1 signaling (31), whereas another report has demonstrated that CHI3L1 is involved in angiogenesis via other mechanisms because CHI3L1 could not be antagonized by anti-VEGFA antibodies (32). The involvement of MCP-1, which has been reported previously (33), was also not clarified in CAFs in the present study. Furthermore, CHI3L1 itself has been reported to be an angiogenic factor $(32,33)$. The results of the present angiogenesis assays also supported this finding, although the difference was not significant. Therefore, despite the present findings demonstrating that CHI3L1 was mainly involved in IL- 8 secretion from CAFs, further studies on the angiogenic effects of CHI3L1 are required. To the best of our knowledge, no reports have demonstrated the roles of fibroblasts in mediating CHI3L1related cancer angiogenesis.

In summary, the results of the present study demonstrated that in the colorectal cancer microenvironment, CHI3L1 is mainly secreted from CAFs and acts on CAFs themselves (Fig. 7). Furthermore, the action of CHI3L1 on CAFs promoted the secretion of IL-8, which induced cancer angiogenesis. CAFs have been reported to affect tumor growth, including cancer cell proliferation, migration, invasion and angiogenesis through the expression or secretion of various proteins $(3,5,7,14,20,21)$, and some of these mechanisms may be related to CHI3L1. Further studies are required to elucidate other functions of CAFs and CHI3L1 in cancer progression and their mechanisms, as well as animal experiments to confirm their effects in vivo. Furthermore, the relationship between the expression levels of CHI3L1 in CAFs and clinicopathological factors, such as venous invasion and metastasis, needs to be clarified in further studies. Treatments targeting the cancer stroma have been attracting increasing attention $(56,57)$. The present study demonstrated that CAFs and CHI3L1 served important roles in cancerstromal interactions and that knockdown of CHI3L1 or addition of anti-CHI3L1 antibodies suppressed angiogenesis. Therefore, targeting the cancer stroma and CHI3L1 could help to establish novel cancer treatments that differ from conventional drugs.

\section{Acknowledgements}

Not applicable.

\section{Funding}

The present study was supported by a Grant-in-Aid for Scientific Research (Japan Society for the Promotion of Science; grant no. 21K08716).

\section{Availability of data and materials}

All data generated or analyzed during this study are included in this published article.

\section{Authors' contributions}

KW, KS, YuM, TH, RO, MH, HT, YoM, AMi, MK and ST designed the study. KW, AMa, SH, TY, TS and HU performed the experiments and acquired the data. KS, YuM, TH, RO, 
MH, HT, YoM, AMi and MK provided technical support in performing the experiments. $\mathrm{KW}, \mathrm{AMi}, \mathrm{MK}$ and $\mathrm{YoM}$ confirmed the authenticity of all data. KW and KS planned all experiments, analyzed and interpreted the data, and drafted the manuscript. All authors are equally responsible for all aspects of the study, including the integrity and accuracy of the data. All authors have read and approved the final manuscript.

\section{Ethics approval and consent to participate}

Ethical approval for the use of human tissue was granted by the Nagoya City University Graduate School of Medical Sciences and Nagoya City University Hospital Institutional Review Board (Nagoya, Japan). Written informed consent was obtained from the patient.

\section{Patient consent for publication}

Not applicable.

\section{Competing interests}

The authors declare that they have no competing interests.

\section{References}

1. Hanahan D and Weinberg RA: The hallmarks of cancer. Cell 100: $57-70,2000$.

2. Liotta LA and Kohn E: The microenvironment of the tumourhost interface. Nature 411: 375-379, 2001.

3. Nakagawa H, Liyanarachchi S, Davuluri RV, Auer H, Martin EW Jr, de la Chapelle A and Frankel WL: Role of cancerassociated stromal fibroblasts in metastatic colon cancer to the liver and their expression profiles. Oncogene 23: 7366-7377, 2004.

4. Shiga K, Hara M, Nagasaki T, Sato T, Takahashi H and Takeyama H: Cancer-associated fibroblasts: Their characteristics and their roles in tumor growth. Cancers (Basel) 7: 2443-2458, 2015.

5. Koliaraki V, Pallangyo CK, Greten FR and Kollias G: Mesenchymal cells in colon cancer. Gastroenterology 152 964-979, 2017.

6. Orimo A and Weinberg RA: Heterogeneity of stromal fibroblasts in tumors. Cancer Biol Ther 6: 618-619, 2007.

7. Nagasaki T, Hara M, Nakanishi H, Takahashi H, Sato M and Takeyama H: Interleukin-6 released by colon cancer-associated fibroblasts is critical for tumour angiogenesis: Anti-interleukin-6 receptor antibody suppressed angiogenesis and inhibited tumourstroma interaction. Br J Cancer 110: 469-478, 2014.

8. Shen J, Zhai J, You Q, Zhang G, He M, Yao X and Shen L: Cancer-associated fibroblasts-derived VCAM1 induced by $H$. pylori infection facilitates tumor invasion in gastric cancer. Oncogene 39: 2961-2974, 2020.

9. Neesse A, Michl P, Frese KK, Feig C, Cook N, Jacobetz MA, Lolkema MP, Buchholz M, Olive KP, Gress TM and Tuveson DA: Stromal biology and therapy in pancreatic cancer. Gut 60: 861-868, 2011.

10. Comito G, Giannoni E, Segura CP, Barcellos-de-Souza P, Raspollini MR, Baroni G, Lanciotti M, Serni S and Chiarugi P: Cancer-associated fibroblasts and M2-polarized macrophages synergize during prostate carcinoma progression. Oncogene 33 : 2423-2431, 2014

11. Cohen N, Shani O, Raz Y, Sharon Y, Hoffman D, Abramovitz L and Erez N: Fibroblasts drive an immunosuppressive and growthpromoting microenvironment in breast cancer via secretion of Chitinase 3-like 1. Oncogene 36: 4457-4468, 2017.

12. Hegab AE, Ozaki M, Kameyama N, Gao J, Kagawa S, Yasuda H, Soejima K, Yin Y, Guzy RD, Nakamura Y, et al: Effect of FGF/FGFR pathway blocking on lung adenocarcinoma and its cancer-associated fibroblasts. J Pathol 249: 193-205, 2019.
13. Kojima Y, Acar A, Eaton EN, Mellody KT, Scheel C, Ben-Porath I, Onder TT, Wang ZC, Richardson AL, Weinberg RA and Orimo A: Autocrine TGF-beta and stromal cell-derived factor-1 (SDF-1) signaling drives the evolution of tumor-promoting mammary stromal myofibroblasts. Proc Natl Acad Sci USA 107: 20009-20014, 2010.

14. Kalluri R and Zeisberg M: Fibroblasts in cancer. Nat Rev Cancer 6: 392-401, 2006.

15. Iwano M, Plieth D, Danoff TM, Xue C, Okada H and Neilson EG: Evidence that fibroblasts derive from epithelium during tissue fibrosis. J Clin Invest 110: 341-350, 2002.

16. Zeisberg EM, Potenta S, Xie L, Zeisberg M and Kalluri R: Discovery of endothelial to mesenchymal transition as a source for carcinoma-associated fibroblasts. Cancer Res 67: 10123$10128,2007$.

17. Mishra PJ, Mishra PJ, Humeniuk R, Medina DJ, Alexe G, Mesirov JP, Ganesan S, Glod JW and Banerjee D: Carcinoma associated fibroblast like differentiation of human mesenchymal stem cells. Cancer Res 68: 4331-4339, 2008.

18. Quante M, Tu SP, Tomita H, Gonda T, Wang SS, Takashi S, Baik GH, Shibata W, Diprete B, Betz KS, et al: Bone marrowderived myofibroblasts contribute to the mesenchymal stem cell niche and promote tumor growth. Cancer Cell 19: 257-272, 2011.

19. Jotzu C, Alt E, Welte G, Li J, Hennessy BT, Devarajan E, Krishnappa S, Pinilla S, Droll L and Song YH: Adipose tissue derived stem cells differentiate into carcinoma-associated fibroblast-like cells under the influence of tumor derived factors. Cell Oncol (Dordr) 34: 55-67, 2011.

20. Wu MH, Hong HC, Hong TM, Chiang WF, Jin YT and Chen YL: Targeting Galectin-1 in carcinoma-associated fibroblasts inhibits oral squamous cell carcinoma metastasis by downregulating MCP-1/CCL2 expression. Clin Cancer Res 17: 1306-1316, 2011.

21. Zhang Y, Tang H, Cai J, Zhang T, Guo J, Feng D and Wang Z: Ovarian cancer-associated fibroblasts contribute to epithelial ovarian carcinoma metastasis by promoting angiogenesis, lymphangiogenesis and tumor cell invasion. Cancer Lett 303: 47-55, 2011.

22. Wei L, Ye H, Li G, Lu Y, Zhou Q, Zheng S, Lin Q, Liu Y, Li Z and Chen R: Cancer-associated fibroblasts promote progression and gemcitabine resistance via the SDF-1/SATB-1 pathway in pancreatic cancer. Cell Death Dis 9: 1065, 2018.

23. Hara M, Nagasaki T, Shiga K and Takeyama H: Suppression of Cancer-associated fibroblasts and endothelial cells by Itraconazole in Bevacizumab-resistant gastrointestinal cancer. Anticancer Res 36: 169-177, 2016.

24. Itoh G, Chida S, Yanagihara K, Yashiro M, Aiba N and Tanaka M: Cancer-associated fibroblasts induce cancer cell apoptosis that regulates invasion mode of tumours. Oncogene 36: 4434-4444, 2017.

25. Hakala BE, White C and Recklies AD: Human cartilage gp-39, a major secretory product of articular chondrocytes and synovial cells, is a mammalian member of a chitinase protein family. J Biol Chem 268: 25803-25810, 1993.

26. Zhao T, Su Z, Li Y, Zhang X and You Q: Chitinase-3 likeprotein-1 function and its role in diseases. Signal Transduct Target Ther 5: 201, 2020.

27. Bara I, Ozier A, Girodet PO, Carvalho G, Cattiaux J, Begueret H, Thumerel M, Ousova O, Kolbeck R, Coyle AJ, et al: Role of YKL-40 in bronchial smooth muscle remodeling in asthma. Am J Respir Crit Care Med 185: 715-722, 2012.

28. Berres ML, Papen S, Pauels K, Schmitz P, Zaldivar MM, Hellerbrand C, Mueller T, Berg T, Weiskirchen R, Trautwein $\mathrm{C}$, et al: A functional variation in $\mathrm{CHI} 3 \mathrm{~L} 1$ is associated with severity of liver fibrosis and YKL-40 serum levels in chronic hepatitis C infection. J Hepatol 50: 370-376, 2009.

29. Volck B, Johansen JS, Stoltenberg M, Garbarsch C, Price PA, Ostergaard M, Ostergaard K, Løvgreen-Nielsen P, Sonne-Holm S and Lorenzen I: Studies on YKL-40 in knee joints of patients with rheumatoid arthritis and osteoarthritis. Involvement of YKL-40 in the joint pathology. Osteoarthritis Cartilage 9: 203-214, 2001.

30. Cintin C, Johansen JS, Christensen IJ, Price PA, Sørensen S and Nielsen HJ: High serum YKL-40 level after surgery for colorectal carcinoma is related to short survival. Cancer 95: 267-274, 2002.

31. Francescone RA, Scully S, Faibish M, Taylor SL, Oh D, Moral L, Yan W, Bentley B and Shao R: Role of YKL-40 in the angiogenesis, radioresistance, and progression of glioblastoma. J Biol Chem 286: 15332-15343, 2011.

32. Shao R, Hamel K, Petersen L, Cao QJ, Arenas RB, Bigelow C, Bentley B and Yan W: YKL-40, a secreted glycoprotein, promotes tumor angiogenesis. Oncogene 28: 4456-4468, 2009. 
33. Kawada M, Seno H, Kanda K, Nakanishi Y, Akitake R, Komekado H, Kawada K, Sakai Y, Mizoguchi E and Chiba T: Chitinase 3-like 1 promotes macrophage recruitment and angiogenesis in colorectal cancer. Oncogene 31: 3111-3123, 2012.

34. Riabov V, Gudima A, Wang N, Mickley A, Orekhov A and Kzhyshkowska J: Role of tumor associated macrophages in tumor angiogenesis and lymphangiogenesis. Front Physiol 5: 75, 2014.

35. Fan JT, Zhou ZY, Luo YL, Luo Q, Chen SB, Zhao JC and Chen QR: Exosomal lncRNA NEAT1 from cancer-associated fibroblasts facilitates endometrial cancer progression via miR-26a/b-5p-mediated STAT3/YKL-40 signaling pathway. Neoplasia 23: 692-703, 2021.

36. Li A, Dubey S, Varney ML, Dave BJ and Singh RK: IL-8 directly enhanced endothelial cell survival, proliferation, and matrix metalloproteinases production and regulated angiogenesis. J Immunol 170: 3369-3376, 2003.

37. Spengler K, Kryeziu N, Große S, Mosig AS and Heller R: VEGF triggers transient induction of autophagy in endothelial cells via AMPK $\alpha 1$. Cells 9: 687, 2020.

38. Chen CC, Pekow J, Llado V, Kanneganti M, Lau CW, Mizoguchi A, Mino-Kenudson $M$, Bissonnette $M$ and Mizoguchi E: Chitinase 3-like-1 expression in colonic epithelial cells as a potentially novel marker for colitis-associated neoplasia. Am J Pathol 179: 1494-1503, 2011.

39. Tang H, Sun Y, Shi Z, Huang H, Fang Z, Chen J, Xiu Q and Li B: YKL-40 induces IL-8 expression from bronchial epithelium via MAPK (JNK and ERK) and NF- $\kappa B$ pathways, causing bronchial smooth muscle proliferation and migration. J Immunol 190: 438-446, 2013

40. Maeda Y, Takahashi H, Nakai N, Yanagita T, Ando N, Okubo T, Saito K, Shiga K, Hirokawa T, Hara M, et al: Apigenin induces apoptosis by suppressing Bcl-xl and Mcl-1 simultaneously via signal transducer and activator of transcription 3 signaling in colon cancer. Int J Oncol 52: 1661-1673, 2018.

41. Bustin SA: Quantification of mRNA using real-time reverse transcription PCR (RT-PCR): Trends and problems. J Mol Endocrinol 29: 23-39, 2002.

42. Zarour LR, Anand S, Billingsley KG, Bisson WH, Cercek A, Clarke MF, Coussens LM, Gast CE, Geltzeiler CB, Hansen L, et al: Colorectal cancer liver metastasis: Evolving paradigms and future directions. Cell Mol Gastroenterol Hepatol 3: 163-173, 2017.

43. Melzer C, von der Ohe J, Lehnert H, Ungefroren H and Hass R: Cancer stem cell niche models and contribution by mesenchymal stroma/stem cells. Mol Cancer 16: 28, 2017.

44. Lee CM, He CH, Nour AM, Zhou Y, Ma B, Park JW, Kim KH, Dela Cruz C, Sharma L, Nasr ML, et al: IL-13Ralpha2 uses TMEM219 in chitinase 3-like-1-induced signalling and effector responses. Nat Commun 7: 12752, 2016.

45. He CH, Lee CG, Dela Cruz CS, Lee CM, Zhou Y, Ahangari F, Ma B, Herzog EL, Rosenberg SA, Li Y, et al: Chitinase 3-like 1 regulates cellular and tissue responses via IL-13 receptor $\alpha 2$. Cell Rep 4: 830-841, 2013.
46. He CH, Lee CG, Ma B, Kamle S, Choi AMK and Elias JA $\mathrm{N}$-glycosylation regulates chitinase 3-like-1 and IL-13 ligand binding to IL-13 receptor $\alpha 2$. Am J Respir Cell Mol Biol 63: 386-395, 2020.

47. Chen Y, Zhang S, Wang Q and Zhang X: Tumor-recruited M2 macrophages promote gastric and breast cancer metastasis via M2 macrophage-secreted CHI3L1 protein. J Hematol Oncol 10: 36, 2017.

48. Brat DJ, Bellail AC and Van Meir EG: The role of interleukin-8 and its receptors in gliomagenesis and tumoral angiogenesis. Neuro Oncol 7: 122-133, 2005.

49. Beard RE, Abate-Daga D, Rosati SF, Zheng Z, Wunderlich JR, Rosenberg SA and Morgan RA: Gene expression profiling using nanostring digital RNA counting to identify potential target antigens for melanoma immunotherapy. Clin Cancer Res 19: 4941-4950, 2013.

50. Kawakami M, Kawakami K, Kasperbauer JL, Hinkley LL, Tsukuda M, Strome SE and Puri RK: Interleukin-13 receptor alpha 2 chain in human head and neck cancer serves as a unique diagnostic marker. Clin Cancer Res 9: 6381-6388, 2003.

51. Joshi BH, Plautz GE and Puri RK: Interleukin-13 receptor alpha chain: A novel tumor-associated transmembrane protein in primary explants of human malignant gliomas. Cancer Res 60: 1168-1172, 2000.

52. Barderas R, Bartolomé RA, Fernandez-Aceñero MJ, Torres S and Casal JI: High expression of IL-13 receptor $\alpha 2$ in colorectal cancer is associated with invasion, liver metastasis, and poor prognosis. Cancer Res 72: 2780-2790, 2012.

53. Geng B, Pan J, Zhao T, Ji J, Zhang C, Che Y, Yang J, Shi H, Li J,Zhou H, et al: Chitinase 3-like 1-CD44 interaction promotes metastasis and epithelial-to-mesenchymal transition through $\beta$-catenin/Erk/Akt signaling in gastric cancer. J Exp Clin Cancer Res 37: 208, 2018

54. Piawah S and Venook AP: Targeted therapy for colorectal cancer metastases: A review of current methods of molecularly targeted therapy and the use of tumor biomarkers in the treatment of metastatic colorectal cancer. Cancer 125: 4139-4147, 2019.

55. Ando N, Hara M, Shiga K, Yanagita T, Takasu K, Nakai N, Maeda Y, Hirokawa T, Takahashi $\mathrm{H}$, Ishiguro $\mathrm{H}$, et al: Eicosapentaenoic acid suppresses angiogenesis via reducing secretion of IL-6 and VEGF from colon cancer-associated fibroblasts. Oncol Rep 42: 339-349, 2019.

56. Togo S, Polanska UM, Horimoto Y and Orimo A: Carcinomaassociated fibroblasts are a promising therapeutic target. Cancers (Basel) 5: 149-169, 2013.

57. Roma-Rodrigues C, Mendes R, Baptista PV and Fernandes AR: Targeting tumor microenvironment for cancer therapy. Int $\mathbf{J} \mathrm{Mol}$ Sci 20: 840, 2019.

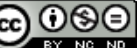

This work is licensed under a Creative Commons Attribution-NonCommercial-NoDerivatives 4.0 International (CC BY-NC-ND 4.0) License. 